\title{
Analysis of couple-stresses and piezo-viscous effects in a layered connecting-rod bearing
}

\author{
Bouzid Laouadi ${ }^{1}$, Mustapha Lahmar $^{1}$, Benyebka Bou-saïd ${ }^{2,}$, Hamid Boucherit $^{1}$, and Ahcene Mouassa ${ }^{1}$ \\ ${ }^{1}$ Département de Génie Mécanique, Laboratoire de Mécanique et Structures (LMS), Université 8 mai 1945 Guelma, \\ BP 401, Guelma (24000), Algeria \\ ${ }^{2}$ Université de Lyon, CNRS INSA-Lyon, LaMCoS, UMR5259, 69621 Lyon, France
}

Received: 14 October 2017 / Accepted: 4 December 2018

\begin{abstract}
In this work, the combined effects of couple-stresses and piezo-viscosity on the dynamic behavior of a compression ignition engine big-end connecting-rod bearing with elastic layer are investigated using the V. K. Stokes micro-continuum theory. It is assumed that the journal (crankpin) is rigid and the big-end bearing consists of a thin compressible elastic liner fixed in an infinitely stiff housing. The governing Reynolds' equation and the viscous dissipation term appearing on the RHS of energy equation are modified using the V. K. Stokes micro-continuum theory. The non-Newtonian effect is introduced by a new material constant $\eta$, which is responsible for couple-stress property, and the piezo-viscosity effect by the pressure-viscosity coefficient $\alpha$ appearing in the well-known Barus' law. In the proposed model, the nonlinear transient modified Reynolds equation is discretized by the finite difference method, and the resulting system of algebraic equations is solved by means of the subrelaxed successive substitutions method to obtain the fluid-film pressure field as well as the film thickness distribution. The crankpin center trajectories for a given load diagram are determined iteratively by solving the nonlinear equilibrium equations of the journal bearing system with the improved and damped Newton-Raphson method for each time step or crankshaft rotation angle. According to the obtained results, the effects of couple-stresses and piezo-viscosity on the nonlinear dynamic behavior of dynamically loaded bearings with either stiff or compliant liners are significant and cannot be overlooked.
\end{abstract}

Keywords: Compression ignition engine / couple-stress / piezo-viscous fluid / coated bearing / dynamically loaded journal bearing

\section{Introduction}

Nowadays, reciprocating machines such as internal combustion engines and compressors are the most important class of machinery extensively used in diverse engineering applications. Unquestionably, dynamic behavior of such machines is strongly dependent on the performance characteristics of their bearings.

The crankshaft and connecting-rod bearings of these modern machines with high horsepower and high loads must be correctly designed to support large dynamic loads resulting from combustion pressure in the engine cylinder and inertia forces due to reciprocating and rotating motions of solids, which belong to the crank-slider mechanism.

These loads, which are generally determined from the crank-slider kinematics and dynamics, vary both in magnitude and direction during an engine cycle. Under

\footnotetext{
* e-mail: Benyebka.Bou-Said@insa-lyon.fr
}

these severe operating conditions, the behavior of the dynamically loaded journal bearing system becomes strongly nonlinear requiring a complete nonlinear transient analysis. This later involves the simultaneous solutions of the complex multiphysical fluid-solid interaction problem, governed by several nonlinear PDEs. This type of analysis is extremely essential when the engine rotates at high speeds, for example, in the case of Formula 1.

Many researchers in the fields of fluid-film lubrication and engine design have tried to formulate lubricants with new chemical compounds to enhance the dynamic behavior of rotating systems. Applications of various types of Newtonian and non-Newtonian fluids or combination of conventional mineral and synthetic-based lubricants with different polymer additives are examples of the efforts made to achieve better dynamic performance characteristics of journal bearing systems.

The rheological behavior of mineral or synthetic motor oils used as lubricants is significantly affected by the presence of various additives such as viscosity index (VI) 
improver polymers, which are characterized by long chains.

These polymers can be classified into two categories: hydrocarbon copolymers and polymethacrylates. In general, oils containing VI additives such as multigrade motor oils must be considered as non-Newtonian shear thinning fluids. Their viscosity decreases when the shear or strain rate to which they are subjected increases, and they are affected by the Weissenberg effect, i.e. during flow, forces appear perpendicular to the shear planes. These properties have been analyzed by a Weissenberg rheogoniometer [1]. According to Lodge [2], these forces could be proportional to the square of the rate of shear.

Rosenberg [3,4] has shown experimentally that the minimum film thickness of a journal bearing lubricated by polymerized oils is more important than that measured with the pure mineral oils having the same viscosity. In order to determine the effects of VI additives on the journal bearing behavior, Robin [5] developed a test bearing. The operating conditions for which the tests were performed are $N=3 \mathrm{krpm}$ and $W_{0}=4 \mathrm{kN}$, which are the rotation velocity of the shaft and the applied load, respectively. It was found that the introduction of high concentration of polymethacrylates to the base mineral oil reduces the friction torque by about $25 \%$ without important change in the film thickness. It was also concluded that it would be interesting to use oils with high concentration of VI additives having low molecular weight such as polymethacrylates, rather than weak concentrations of additives with high molecular weight.

In the Oliver's experimental work [6], it was found that the presence of dissolved polymer in the lubricant increases the load carrying capacity of the lubricating film and decreases the friction coefficient.

In another experimental investigation, Scott and Suntiwattana [7] showed that addition of a small amount of long-chained additives like some polymers such as polyisobutylene can enhance the lubricating effectiveness of conventional Newtonian lubricant.

The microstructure of these new lubricants can translate, rotate and deform independently.

It is observed from the experimental results that using the micro-continuum or micro-polar theory is more suitable for the theoretical study of such lubricants. Application of classical Navier-Stokes and energy equations to describe their motion leads to erroneous results. Thus, many rheological models such as power law, viscoelastic, couplestress and micro-polar are proposed in the technical literature.

In order to better describe the rheological behavior of this kind of lubricant, different micro-continuum theories have been developed. The Stokes' micro-continuum theory $[8,9]$ is the simplest theory of fluids proposed in the technical literature since the 1960 s, which allows the polar effects such as the presence of couple-stresses and body couples in addition to the body forces and surface forces. However, it neglects the elasticity and the normal forces effects appearing during flow because of the presence of such additives.

In this theory, the iso-volume couple-stress fluids are characterized by two constants, namely, $\mu$ and $\eta$, whereas only one parameter appears for a Newtonian iso-volume fluid, which is the dynamic viscosity $\mu$. The new material constant $\eta$ is responsible for couple-stress property. In the literature, the effects of couple-stresses on the behavior of journal bearings are generally studied by defining the couple-stress parameter $l=\left(\frac{\eta}{\mu}\right)^{\frac{1}{2}}$ which has the dimension of length and can be thought of as a fluid property depending on the size of the polymer molecule.

In an excellent investigation, Fatu et al. [10] have studied the importance of piezo-viscous and shearthinning effects on the dynamic behavior of three typical compliant connecting-rod big-end bearings used for a Formula 1 engine, a compression ignition engine and a spark ignition engine. The constitutive equation relating the fluid dynamic viscosity to rate of shear that has been used by the authors to describe the non-Newtonian shear thinning behavior is similar to that proposed by Gecim [11].

To study the piezo-viscous effects, the model that has been used by the authors is that suggested by Chu and Cameron, which is suitable for higher pressures [12].

They proved that for the studied cases, the nonNewtonian shear thinning effects could not be neglected, especially for high-speed engines, and the piezo-viscous effects are more significant than the non-Newtonian effects and lead to increasing film thickness.

It should be noted that the same constitutive equation has been used by Paranjpe [13], and Wang et al. $[14,15]$ in order to investigate the non-Newtonian shear-thinning effects in smooth and rough dynamically loaded bearings.

In an earlier work [16], we have presented a theoretical study of stiff big-end connecting-rod bearings dynamic behavior for both Diesel and gasoline engines using the couple-stress fluid model. The mobility method [17,18] suggested in 1965 by Booker has been adopted to the numerical treatment of nonlinear motion equations of the rigid crankpin. The effects of different values of couplestress parameter $l$ on the minimum film thickness, peak pressure, flow rate, power loss as well as crankpin trajectories were investigated for both engines.

In the present work, which can be considered as an extension of the above work [16], the combined effects of couple-stresses and piezo-viscosity on the dynamic behavior of a compression ignition engine big-end connectingrod bearing with elastic layer are investigated using the Stokes micro-continuum theory. It is assumed that the journal (crankpin) is rigid and the big-end bearing consists of a thin compressible elastic liner fixed in an infinitely stiff housing.

The damped Newton-Raphson method is used, in improved form, to predict the dynamic response of layered connecting-rod bearings subjected to a load cycle instead of the mobility method since this later is not appropriate for the analysis of compliant or partially grooved journal bearings despite its rapidity to obtain dynamic responses of stiff cylindrical journal bearings [19]. However, when using the Newton-Raphson method, the inverse lubrication problem needs to be solved instead of the direct problem, i.e. dynamical loads applied on bearing are known but 
corresponding eccentricities of journal need to be calculated by iteration.

\section{Theoretical analysis}

\subsection{Governing equations of couple-stress fluid mechanics}

The governing equations for the transient flow of an incompressible (iso-volume) couple-stress fluid, neglecting the body forces and body couples, can be written in the general form as $[8,9]$

$$
\begin{gathered}
\frac{\partial v_{i}}{\partial x_{i}}=0 \\
\rho\left(\frac{\partial v_{i}}{\partial t}+v_{j} \frac{\partial v_{i}}{\partial x_{j}}\right)=\frac{\partial T_{j i}}{\partial x_{j}},
\end{gathered}
$$

where $\quad T_{j i}=-p \delta_{i j}+\mu\left(\frac{\partial v_{i}}{\partial x_{j}}+\frac{\partial v_{j}}{\partial x_{i}}\right)-\eta \nabla^{2}\left(\frac{\partial v_{i}}{\partial x_{j}}-\frac{\partial v_{j}}{\partial x_{i}}\right)$, which is the total skew symmetric stress tensor, and $\nabla^{2}=\frac{\partial^{2}}{\partial x_{k} \partial x_{k}}$ is the Laplace operator.

$$
\begin{aligned}
\underbrace{\rho C_{p}\left(\frac{\partial T}{\partial t}+v_{j} \frac{\partial T}{\partial x_{j}}\right)}_{\text {Energy transfer due to convection }}= & \underbrace{\frac{\partial}{\partial x_{i}}\left(k \frac{\partial T}{\partial x_{i}}\right)}_{\text {Energy transfer due to conduction }} \\
& +\underbrace{2 \mu D_{i j} D_{i j}+16 \eta K_{i} K_{i}}_{\text {Total viscous dissipation } \Phi}
\end{aligned}
$$

where $D_{i j}=\frac{1}{2}\left(\frac{\partial v_{i}}{\partial x_{j}}+\frac{\partial v_{j}}{\partial x_{i}}\right)$ and $K_{i}=\frac{1}{2} \varepsilon_{i j k} \omega_{k, j}=-\frac{1}{4} \frac{\partial^{2} v_{i}}{\partial x_{j} \partial x_{j}}$, which are the strain rate tensor and the mean curvature rate vector, respectively.

These are the equations of conservation of mass, conservation of linear momentum and conservation of energy, respectively.

Although it is not necessary for the present analysis, the modified energy equation has been derived only for the purpose of giving the expression of the dissipation function appearing on the RHS of equation (3), which will be useful for calculating the power loss.

\subsection{Modified Reynolds equation for piezo-viscous fluids with couple-stress}

With the usual assumptions considered for the lubrication film, the modified Reynolds equation for two-dimensional isothermal flow of piezo-viscous lubricant with couplestress can be derived for the connecting-rod big-end bearing represented in Figure 1 [20].

$$
\begin{aligned}
& \frac{\partial}{\partial x}\left[G(h, l, \alpha, p) \frac{\partial p}{\partial x}\right]+\frac{\partial}{\partial z}\left[G(h, l, \alpha, p) \frac{\partial p}{\partial z}\right] \\
& =12 \mu_{0}\left(\bar{\omega}(t) R \frac{\partial h}{\partial x}+\frac{\partial h}{\partial t}\right),
\end{aligned}
$$

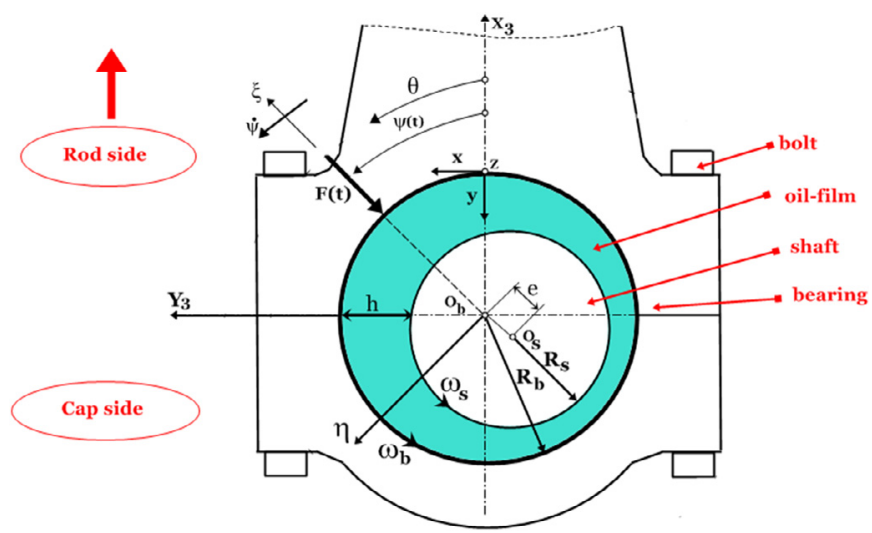

Fig. 1. Big-end connecting-rod bearing and coordinates systems.

where

$$
\begin{aligned}
G(h, l, \alpha, p)= & h^{3} e^{-\alpha p}-12 l^{2} \\
& \times\left[h e^{-2 \alpha p}-2 l e^{-\frac{5}{2} \alpha p} \tanh \left(\frac{h e^{\frac{1}{2} \alpha p}}{2 l}\right)\right] \text { and } \\
\bar{\omega}(t)= & \frac{\omega_{s}+\omega_{b}}{2}=\frac{\omega_{2}}{2}\left(1-\frac{\ell_{2}}{\ell_{3}} \cos \theta_{2}(t)\right)
\end{aligned}
$$

where $\omega_{s}$ is the shaft (crankpin) angular velocity, $\omega_{b}$ is the big-end bearing angular velocity, $\omega_{2}=\frac{2 \pi N}{60}$ is the angular velocity of crankshaft ( $N$ being the engine rotational speed in rpm), $\theta_{2}$ is the crankshaft angle, which varies from 0 to $4 \pi, \frac{\ell_{2}}{\ell_{3}}$ is the ratio of the crankshaft-arm length to the connecting-rod length and $\bar{\omega}$ is the mean angular velocity determined from the kinematics analysis of crank-slider mechanism [18].

Note that for crankshaft bearings (main bearings), equation (5) reduces to $\bar{\omega}(t)=\frac{\omega_{2}}{2}$.

In the above equations, $h$ is the lubricant film thickness, $l$ has the dimension of length and can be regarded as a fluid property depending on the size of the high polymer molecule and as it approaches to zero, equation (4) reduces to the classical Reynolds equation for Newtonian fluid. $\alpha$ is the pressure-viscosity coefficient appearing in the Barus law, which gives the viscosity-pressure dependency at constant temperature:

$$
\mu(p)=\mu_{0} e^{\alpha p}
$$

where $\mu_{0}$ is the dynamic viscosity for $p=0$, and $\alpha$ is the pressure-viscosity coefficient, which can be obtained by plotting the natural logarithm of dynamic viscosity $\mu$ versus pressure $p$. The slope of the graph corresponds to the value of $\alpha$. The pressure--viscosity coefficient is a function of the molecular structure of the lubricant and its physical characteristics.

There are various formulae available to calculate the pressure-viscosity coefficient in the technical literature such as the Wooster's relationship [21]. Some of these equations are accurate for certain fluids and inaccurate for others. 
It should be noted that the piezo-viscosity effect varies between oils, and it is more considerable for naphthenic oils than paraffinic oils. Water, by contrast, shows only a small rise, almost negligible, in viscosity variation with pressure.

There are many other formulae for viscosity-pressure relationships. A short review of some of the empirical formulae for the viscosity-pressure relationships is given in reference [22].

\subsection{Boundary conditions}

The boundary conditions associated to the Reynolds equation (4) may be classified as follows:

Boundary conditions related to the environment in which the system operates:

$$
p\left(x, z= \pm \frac{L}{2}, t\right)=p_{a t m}=0, \text { at the bearing edges }
$$

Periodicity condition:

$$
p(x=0, z, t)=p(x=2 \pi R, z, t)
$$

Boundary related to lubricant supply:

$$
p=p_{s}=0 \text {, at the feeding groove }
$$

Boundary conditions related to lubricant flow (cavitation phenomenon):

$$
\begin{cases}p(x, z, t)=p_{\text {cav }}=0 & \text { at the oil film rupture } \\ \frac{\partial p}{\partial x}(x, z, t)=\frac{\partial p}{\partial z}(x, z, t)=0, & \text { boundary }\end{cases}
$$

At these conditions, we can add for aligned journal bearings the following condition:

$$
\frac{\partial p}{\partial z}(x, z=0, t)=0, \text { at the bearing centerline }
$$

\subsection{Oil film thickness}

The connecting-rod housing and the crankpin are considered as infinitely stiff and thus only the thin compliant liner will deform Figure 1 . In the mobile frame $\left(X_{3}, Y_{3}\right)$ related to the connecting-rod, the film thickness of the undeformed bearing is a function of the radial clearance $C=R_{b}-R_{s}$ and the crankpin center position defined by $e_{X}$ and $e_{Y}$ as expressed in the following equation:

$$
h_{0}=C-e_{X}(t) \cos \theta-e_{Y}(t) \sin \theta,
$$

where $\theta$ is the bearing angle (cylindrical coordinate) originating at the $X$-axis.

When the film thickness $h_{0}$ is modified with the elastic deformation of the fluid film-bearing liner interface, the film geometry becomes

$$
h(\theta, z, t)=h_{0}+C_{X} P(\theta, z, t),
$$

where $C=\frac{(1+\sigma)(1-2 \sigma)}{1-\sigma} \frac{t_{l}}{E}$ is the compliance operator of the bearing liner in $(\mathrm{m} / \mathrm{Pa})$. This operator gives a relation between pressure and elastic displacement and not between force and displacement.

The simplified elastic model used in equation (9) to calculate the radial deformation due to hydrodynamic pressure is more accurate when we assume that the liner thickness, $t_{l}$, is much smaller than the bearing radius, i.e. $\frac{t_{l}}{R} \ll 1[23-25]$.

The bearing configuration considered is similar to that recently studied by Thomsen and Klit using a three-node triangular finite element method for solving Reynolds equation [26]. In this study, where only the local deformations of the bearing liner are considered, the authors have used the same elastic model to calculate the radial displacement at the fluid film-bearing liner interface. The liner is made of an almost incompressible material, namely, the PEEK (Polyetheretherketone) composite having a modulus of elasticity $E$ of $6 \mathrm{GPa}$ and a Poisson's ratio $\sigma$ of 0.40 .

Note that the compliance operator $C$, which is considered as a key parameter in EHD problems, can be determined in matrix form, called compliance matrix, using a standard finite element or boundary element analysis of the whole bearing structure.

\subsection{Finite difference formulation of the modified Reynolds equation}

The finite difference method is used to approach the nonlinear transient pressure equation (4) called here the modified Reynolds' equation.

The bearing surface is divided into $N_{x} \times N_{z}$ rectangular cells, i.e. the total number of nodes is $\left(N_{x}+1\right) \times\left(N_{z}+1\right)$. A computational grid of $61 \times 21$ nodal points is selected for the present investigation. This computational size is chosen as a compromise between time of calculations and accuracy.

After discretization, the modified Reynolds equation takes the following form:

$$
\begin{aligned}
& \underbrace{\left(\frac{\mathrm{G}_{i+\frac{1}{2}, j}+\mathrm{G}_{i-\frac{1}{2}, j}}{(\triangle x)^{2}}+\frac{\left(\mathrm{G}_{i, j+\frac{1}{2}}+\mathrm{G}_{i, j-\frac{1}{2}}\right)}{(\triangle z)^{2}}\right)}_{a_{i, j}} p_{i, j} \\
& =\underbrace{\left(\frac{\mathrm{G}_{i+\frac{1}{2}, j}}{(\triangle x)^{2}}\right)}_{b_{i, j}} p_{i+1, j}+\underbrace{\left(\frac{\mathrm{G}_{i-\frac{1}{2}, j}}{(\triangle x)^{2}}\right)}_{c_{i, j}} p_{i-1, j} \\
& +\underbrace{\left(\frac{\mathrm{G}_{i, j+\frac{1}{2}}}{\left(\triangle_{z}\right)^{2}}\right)}_{d_{i, j}} p_{i, j+1}+\underbrace{\left(\frac{\mathrm{G}_{i, j-\frac{1}{2}}}{(\triangle z)^{2}}\right)}_{e_{i, j}} p_{i, j-1} \\
& -12 \mu_{0}\left[\bar{\omega} R\left(\frac{h_{i+1, j}-h_{i-1, j}}{2 \triangle x}+\frac{h_{i j}^{t}-h_{i j}^{t-\triangle t}}{\triangle t}\right]\right.
\end{aligned}
$$


where $\quad \mathrm{G}_{i+\frac{1}{2}, j}=\frac{\mathrm{G}_{i, j}+\mathrm{G}_{i+1, j}}{2} ; \quad \mathrm{G}_{i-\frac{1}{2}, j}=\frac{\mathrm{G}_{i, j}+\mathrm{G}_{i-1, j}}{2} ; \quad \mathrm{G}_{i, j+\frac{1}{2}}=$ $\frac{\mathrm{G}_{i, j}+\mathrm{G}_{i, j+1}}{2} ; \mathrm{G}_{i, j-\frac{1}{2}}=\frac{\mathrm{G}_{i, j}+\mathrm{G}_{i, j-1}}{2} ; h_{i j}^{t-\triangle t}$ is the nodal oil film thickness calculated at previous time steps, $i=1, \ldots, N_{x}+1$ and $\mathrm{j}=1, \ldots, N_{z}$.

In equation (10), $\triangle x=\frac{2 \pi}{N_{x}}, \triangle z=\frac{L}{2 N_{z}}$ are the mesh sizes in the circumferential and axial directions, respectively, and $\triangle t=\left|\frac{\triangle \theta_{2}}{\omega_{2}}\right|$ is the time increment. $\triangle \theta_{2}=\frac{4 \pi}{n s t e p s}$ being the crank angle increment where nsteps is the number of steps in one engine cycle, i.e. the complete load cycle divided into nsteps parts. So, the total number of data will be (nsteps +1$)$, including the first and the last data (e.g. for $\triangle \theta_{2}=5^{\circ}$, nsteps $=144$, and for $\triangle \theta_{2}=1^{\circ}$, nsteps $=720)$.

The nonlinear algebraic equations system (10) resulting from the spatial-temporal discretization of the nonlinear modified Reynolds equation is solved by the successive substitution method with underrelaxation coefficient $\omega$ ranging from 0 to 1 similar to the one-dimensional nonlinear root finding Wegstein's method in order to determine the oil film pressure field $p_{i, j}$ :

$$
p_{i j}^{(m)}=(1-\omega) p_{i j}^{(m-1)}+\omega p_{i j}^{(m)}
$$

where the superscript $m$ indicates the number of iteration for the successive substitution method.

Typical $\omega$ values selected for the cases studied in this work range from $10^{-3}$ to $10^{-1}$ depending on the nonlinear behavior of the modified Reynolds equation. However, $\omega$ can be equal to 1 when solving the linear Reynolds equation, i.e. for stiff bearing and/or isoviscous cases.

This method consists of building up a series of solutions $p_{i j}^{(0)}, p_{i j}^{(1)}, \ldots \ldots, p_{i j}^{(m-1)}, p_{i j}^{(m)}$, where $p_{i j}^{(0)}$ the initial estimate of solution. The nodal pressures $p_{i j}^{(m)}$ being calculated by solving the following system by the GaussSeidel algorithm with overrelaxation coefficient $\Omega_{G S}$ in order to accelerate the procedure convergence, especially when dealing with transient and nonlinear problems, and to fulfill the Reynolds cavitation conditions $(7 \mathrm{~d})$ by incorporating the Christopherson algorithm [27]. During the iterative computation of fluid film pressure, the pressure vanishes $\left(p_{\text {cav }}=0\right)$ if the calculated pressure becomes negative:

$$
\begin{aligned}
\left(p_{i j}^{(m)}\right)^{n+1}= & \left(1-\Omega_{G S}\right)\left(p_{i j}^{(m)}\right)^{n}+\Omega_{G S}\left(\left(b_{i, j}\right)^{(m-1)}\left(p_{i+1, j}^{(m)}\right)^{n}\right. \\
& +\left(c_{i, j}\right)^{(m-1)}\left(p_{i-1, j}^{(m)}\right)^{n+1}+\left(d_{i, j}\right)^{(m-1)}\left(p_{i, j+1}^{(m)}\right)^{n} \\
& +\left(e_{i, j}\right)^{(m-1)}\left(p_{i, j-1}^{(m)}\right)^{n+1} \\
& \left.-\left(f_{i, j}\right)^{(m-1)}\right) /\left(a_{i, j}\right)^{(m-1)}
\end{aligned}
$$

where $(n)$ and $(n+1)$ are the steps of Gauss-Seidel iteration.

The iterative Gauss-Seidel procedure is stopped when at each grid point (node $i, j$ ) the maximum relative error between two successive iterations fell below a tolerant error of $10^{-6}$, i.e.

$$
\max \left|\frac{\left(p_{i j}^{(m)}\right)^{(n+1)}-\left(p_{i j}^{(m)}\right)^{(n)}}{\left(p_{i j}^{(m)}\right)^{(n+1)}}\right| \leq 10^{-6} .
$$

Note that in relaxation methods, the execution time or even the numerical stability is greatly affected by the relaxation coefficient used. The optimum value for $\Omega_{G S}$ is not always predictable in advance [28].

The optimum value of $\Omega_{G S}$ is that which is able to converge to the solution for a tolerant error in a minimum number of iterations or a small computing time. In practice, it is generally determined via numerical simulations.

The stopping criterion of iterations in the successive substitution algorithm is

$$
\|n\|=\sqrt{\frac{\sum_{i=1}^{N_{x+1}} \sum_{j=1}^{N_{z+1}}\left(p_{i j}^{(m)}-p_{i j}^{(m-1)}\right)^{2}}{\sum_{i=1}^{N_{x+1}} \sum_{j=1}^{N_{z+1}}\left(p_{i j}^{(m)}\right)^{2}}} \leq 10^{-2}
$$

$\|n\|$ being the relative least square norm.

\subsection{Load balance and crankpin center orbit}

When the external load acting on the bearing varies both in direction and magnitude, the journal (crankpin) center describes a trajectory within the bearing. The determination of this trajectory requires the solution of the nonlinear equilibrium equations at each time step or crank rotation angle with an iterative method. An inverse solution of the Reynolds' equation is then required.

For an aligned journal bearing, the equilibrium equations may be written when inertia forces of the crankpin are neglected as

$$
\left\{\begin{array}{l}
-\iint_{A} p \cos \theta d A+F_{X}=0 \\
-\iint_{A} p \sin \theta d A+F_{Y}=0
\end{array}\right.
$$

where $F_{X}, F_{Y}$ are the applied load components.

At each time, the position of the journal (crankpin) center defined by the eccentricity vector $\boldsymbol{e}(t)=\left\{\begin{array}{l}e_{X}(t) \\ e_{Y}(t)\end{array}\right\}$ is determined when the lift force vector $\boldsymbol{W}(t)=$ $\left\{\begin{array}{l}W_{X}(t) \\ W_{Y}(t)\end{array}\right\}=-\iint_{A} p\left\{\begin{array}{l}\cos \theta \\ \sin \theta\end{array}\right\} d A$ balances the applied load $\boldsymbol{F}(t)=\left\{\begin{array}{l}F_{X}(t) \\ F_{Y}(t)\end{array}\right\}$ expressed in the mobile coordinate system related to the connecting-rod $\left(X_{3}, Y_{3}\right)$. 
Equation (15) can be rewritten as

$\left\{\begin{array}{l}r_{X}\left(e_{X}(t), e_{Y}(t)\right)=\int_{-\frac{L}{2}}^{\frac{L}{2}} \int_{\theta_{1}}^{\theta_{2}} p(\theta, z, t) \cos \theta R d \theta d z-F_{X}(t)=0 \\ r_{Y}\left(e_{X}(t), e_{Y}(t)\right)=\int_{-\frac{L}{2}}^{\frac{L}{2}} \int_{\theta_{1}}^{\theta_{2}} p(\theta, z, t) \sin \theta R d \theta d z-F_{Y}(t)=0\end{array}\right.$

where $r_{X}$ and $r_{Y}$ are the components of the residual vector $\boldsymbol{r}(t)$, which is a nonlinear function of $e_{X}$ and $e_{Y}$.

The damped Newton-Raphson method is used to solve the set of two nonlinear equations (16a). This method is formulated on the linearization of equilibrium equations using two variables, Taylor expansion of equations (16a) in the neighborhood of the $k$ th trial solution $\left\{\begin{array}{c}e_{X}^{(k)}(t) \\ e_{Y}^{(k)}(t)\end{array}\right\}$, i.e.

$$
\left\{\begin{array}{l}
r_{X}^{(k+1)} \approx r_{X}^{(k)}+\left(\frac{\partial r_{X}}{\partial e_{X}}\right)_{k} \delta e_{X}^{(k)}+\left(\frac{\partial r_{X}}{\partial e_{Y}}\right)_{k} \delta e_{Y}^{(k)}=0 \\
r_{Y}^{(k+1)} \approx r_{Y}^{(k)}+\left(\frac{\partial r_{Y}}{\partial e_{X}}\right)_{k} \delta e_{X}^{(k)}+\left(\frac{\partial r_{Y}}{\partial e_{Y}}\right)_{k} \delta e_{Y}^{(k)}=0
\end{array} .\right.
$$

In the relaxed Newton-Raphson method, the $(k+1)$ th trial solution is

$$
\left\{\begin{array}{l}
e_{X}^{(k+1)}(t) \\
e_{Y}^{(k+1)}(t)
\end{array}\right\}=\left\{\begin{array}{c}
e_{X}^{(k)}(t) \\
e_{Y}^{(k)}(t)
\end{array}\right\}+\omega_{N R}\left\{\begin{array}{c}
\delta e_{X}^{(k)}(t) \\
\delta e_{Y}^{(k)}(t)
\end{array}\right\}
$$

where $\omega_{N R}$ is the damping factor in the interval $(0,1)$.

It was found during simulations that for liners with low elasticity modulus and for piezo-viscous lubricants leading to a nonlinear Reynolds equation, the use of the damped Newton-Raphson method described above with $\omega_{N R}=10^{-1}$ is required in order to obtain the numerical convergence. On the other hand, for rigid liner and/or isoviscous lubricant, the $\omega_{N R}$ value can be taken to be equal to 1 , because in such a case both Newtonian and nonNewtonian Reynolds equations have a linear behavior in terms of pressure $p$.

Note that the $\omega_{N R}$ value can be automatically adjusted during iterations based on the rate of solution convergence.

The corrections $\left\{\begin{array}{c}\delta e_{X}^{(k)}(t) \\ \delta e_{Y}^{(k)}(t)\end{array}\right\}$ to $\left\{\begin{array}{c}e_{X}^{(k)}(t) \\ e_{Y}^{(k)}(t)\end{array}\right\}$ are found by solving the following linear algebraic system deduced from equation (16b)

See equation (18) below.
The obtained linear system is solved analytically.

The stopping criterion for the improved NewtonRaphson method by which the iterative process can be ended without any loss in solution accuracy is

$$
\left|r_{X}^{(k)}(t)\right|+\left|r_{Y}^{(k)}(t)\right| \leq \varepsilon \quad \text { and } \quad k<k_{\max },
$$

which represents the Laplace's norm $L_{1}$ of the residual.

The Euclidean $L_{2}$ norm of the residual can also be used, i.e.

$$
\left\{\begin{array}{c}
r_{X}^{(k)}(t) \\
r_{Y}^{(k)}(t)
\end{array}\right\}\left\{\begin{array}{c}
r_{X}^{(k)}(t) \\
r_{Y}^{(k)}(t)
\end{array}\right\} \leq \varepsilon,
$$

where $\varepsilon=10^{-2}$ and $k_{\max }$ are the predefined convergence tolerance and the maximum number of iterations, respectively.

The partial derivatives appearing in matrix equation (18) are evaluated numerically by central finite differences, i.e.

$$
\begin{aligned}
& \left(\frac{\partial r_{X}}{\partial e_{X}}\right)_{k} \approx \frac{r_{X}\left(e_{X}^{(k)}+\delta, e_{Y}^{(k)}\right)-r_{X}\left(e_{X}^{(k)}-\delta, e_{Y}^{(k)}\right)}{2 \delta} ; \\
& \left(\frac{\partial r_{X}}{\partial e_{Y}}\right)_{k} \approx \frac{r_{X}\left(e_{X}^{(k)}, e_{Y}^{(k)}+\delta\right)-r_{X}\left(e_{X}^{(k)}, e_{Y}^{(k)}-\delta\right)}{2 \delta} ; \\
& \left(\frac{\partial r_{Y}}{\partial e_{X}}\right)_{k} \approx \frac{r_{Y}\left(e_{X}^{(k)}+\delta, e_{Y}^{(k)}\right)-r_{Y}\left(e_{X}^{(k)}-\delta, e_{Y}^{(k)}\right)}{2 \delta} ; \\
& \left(\frac{\partial r_{Y}}{\partial e_{Y}}\right)_{k} \approx \frac{r_{Y}\left(e_{X}^{(k)}, e_{Y}^{(k)}+\delta\right)-r_{Y}\left(e_{X}^{(k)}, e_{Y}^{(k)}-\delta\right)}{2 \delta}
\end{aligned}
$$

where $\delta=10^{-10}$ for calculations made in double precision.

\subsection{Hydrodynamic characteristics}

\subsubsection{Side leakage flow}

The side leakage flow at bearing edges $\left(z= \pm \frac{L}{2}\right)$ is calculated by the following relation:

$$
Q_{z}=2\left|\int_{\theta_{1}^{*}}^{\theta_{2}^{*}} h\left(\theta, z=\frac{L}{2}\right)\left\langle w\left(\theta, z=\frac{L}{2}\right)\right\rangle R d \theta\right|
$$

where $\theta_{1}^{*}(t)$ and $\theta_{2}^{*}(t)$ are the angles delimiting the active zone of the bearing.

$$
\left[\begin{array}{cc}
\left(\frac{\partial r_{X}}{\partial e_{X}}\right)^{2}+\left(\frac{\partial r_{Y}}{\partial e_{X}}\right)^{2} & \frac{\partial r_{X}}{\partial e_{X}} \frac{\partial r_{X}}{\partial e_{Y}}+\frac{\partial r_{Y}}{\partial e_{X}} \frac{\partial r_{Y}}{\partial e_{Y}} \\
\text { Sym. } & \left(\frac{\partial r_{X}}{\partial e_{Y}}\right)^{2}+\left(\frac{\partial r_{Y}}{\partial e_{Y}}\right)^{2}
\end{array}\right]_{\left(e_{X}^{(k)}, e_{Y}^{(k)}\right)}\left\{\begin{array}{c}
\delta e_{X}^{(k)}(t) \\
\delta e_{Y}^{(k)}(t)
\end{array}\right\}=-\left\{\begin{array}{l}
r_{X} \frac{\partial r_{X}}{\partial e_{X}}+r_{Y} \frac{\partial r_{Y}}{\partial e_{X}} \\
r_{X} \frac{\partial r_{X}}{\partial e_{Y}}+r_{Y} \frac{\partial r_{Y}}{\partial e_{Y}}
\end{array}\right\}_{\left(e_{X}^{(k)}, e_{Y}^{(k)}\right)}
$$


In the above equations, $h$ is the film thickness and $\langle w(x, z)\rangle=\frac{1}{h} \int_{0}^{h} w(x, y, z) d y$ is the axial mean flow velocity calculated by the following relationship obtained for piezoviscous couple-stress fluid:

$$
\langle w(x, z)\rangle=-\frac{G(h, l, \alpha, p)}{12 \mu_{0} h} \frac{\partial p}{\partial z} .
$$

The axial flow velocity $w(x, y, z)$ as well as the circumferential velocity $u(x, y, z)$ is determined from integration of field equations governing the motion of the lubricating oil in $x$ - and $z$-directions:

$$
\begin{gathered}
\eta \frac{\partial^{4} u}{\partial y^{4}}-\mu_{0} e^{\alpha p} \frac{\partial^{2} u}{\partial y^{2}}=-\frac{\partial p}{\partial x} . \\
\eta \frac{\partial^{4} w}{\partial y^{4}}-\mu_{0} e^{\alpha p} \frac{\partial^{2} w}{\partial y^{2}}=-\frac{\partial p}{\partial z} .
\end{gathered}
$$

Using the following boundary conditions,

$$
\begin{aligned}
u(x, 0, z) & =U_{b}=\omega_{b} R, \frac{\partial^{2} u}{\partial y^{2}}(x, 0, z)=0, u(x, h, z) \\
& =U_{s}=\omega_{s} R, \quad \text { and } \quad \frac{\partial^{2} u}{\partial y^{2}}(x, h, z)=0
\end{aligned}
$$

$$
\begin{aligned}
w(x, 0, z) & =0, \frac{\partial^{2} w}{\partial y^{2}}(x, 0, z)=0, w(x, h, z) \\
& =0, \quad \text { and } \quad \frac{\partial^{2} w}{\partial y^{2}}(x, h, z)=0,
\end{aligned}
$$

we get

See equations (25a) and (25b) below.

\subsection{Power loss}

The total power loss is evaluated on the active zone of bearing from

$$
\mathcal{P}=\left|\mathcal{P}_{\text {Couette \& Hagen-Poiseuille }}\right|+\left|\mathcal{P}_{\text {squeeze }}\right|,
$$

where

$$
\begin{aligned}
\mathcal{P}_{\text {Couette\& Hagen-Poiseuille }} & =\int_{-\frac{L}{2}}^{\frac{L}{2}} \int_{\theta_{1}^{*}}^{\theta_{2}^{*}} \int_{0}^{h} \Phi_{1} d y R d \theta d z \\
& +\int_{-\frac{L}{2}}^{\frac{L}{2}} \int_{\theta_{1}^{*}}^{\theta_{2}^{*}} \int_{0}^{h} \Phi_{2} d y R d \theta d z
\end{aligned}
$$

In equation (27), $\Phi_{1}$ and $\Phi_{2}$ are the dissipation functions due to the shear stress and the couple-stress effects, respectively. These two functions that appear on the second hand of modified energy equation (3) can be defined in hydrodynamic lubrication theory as

$$
\begin{aligned}
\Phi_{1} & =2 \mu D_{i j} D_{i j} \\
& =\mu\left(\frac{\partial v_{i}}{\partial x_{j}} \frac{\partial v_{i}}{\partial x_{j}}+\frac{\partial v_{i}}{\partial x_{j}} \frac{\partial v_{j}}{\partial x_{i}}\right) \approx \mu\left[\left(\frac{\partial u}{\partial y}\right)^{2}+\left(\frac{\partial w}{\partial y}\right)^{2}\right], \\
\Phi_{2} & =16 \eta K_{i} K_{i} \\
& =\eta \frac{\partial^{2} v_{i}}{\partial x_{j} \partial x_{j}} \frac{\partial^{2} v_{i}}{\partial x_{k} \partial x_{k}} \approx \eta\left[\left(\frac{\partial^{2} u}{\partial y^{2}}\right)^{2}+\left(\frac{\partial^{2} w}{\partial y^{2}}\right)^{2}\right] .
\end{aligned}
$$

After integration with respect to $y$, we get

$\mathcal{P}_{\text {Couette \& Hagen-Poiseuille }}$

$$
\begin{aligned}
= & \underbrace{\int_{-\frac{L}{2}}^{\frac{L}{2}} \int_{\theta_{1}^{*}}^{\theta_{2}^{*}} \frac{\mu_{0} e^{\alpha p}\left(U_{s}-U_{b}\right)^{2}}{h} R d \theta d z}_{\text {Shear induced power }} \\
& +\underbrace{\int_{-\frac{L}{2}}^{\frac{L}{2}} \int_{\theta_{1}^{*}}^{\theta_{2}^{*}} \frac{G(h, l, \alpha, p)}{12 \mu_{0}}\left[\left(\frac{\partial p}{R \partial \theta}\right)^{2}+\left(\frac{\partial p}{\partial z}\right)^{2}\right]}_{\text {Pressure induced power }} R d \theta d z
\end{aligned}
$$

and

$$
\mathcal{P}_{\text {squeeze }}=\boldsymbol{F} \cdot \dot{\boldsymbol{e}}=F_{X} \cdot \dot{e}_{X}+F_{Y} \cdot \dot{e}_{Y},
$$

which is the power loss due to the squeezing effect.

$$
\begin{aligned}
& u(x, y, z)=\underbrace{U_{b}+\left(U_{s}-U_{b}\right) \frac{y}{h}}_{\text {Couetteflow }}+\underbrace{\frac{e^{-2 \alpha p}}{2 \mu_{0}} \frac{\partial p}{\partial x}\left\{\frac{y(y-h)}{e^{-\alpha p}}+2 \ell^{2}\left[1-\frac{\operatorname{Cosh}\left(\frac{2 y-h}{2 \ell e^{-\frac{1}{2} \alpha p}}\right)}{\operatorname{Cosh}\left(\frac{h}{2 \ell e^{-\frac{1}{2} \alpha p}}\right)}\right]\right\}}_{\text {Hagen-Poiseuilleflow }} \\
& w(x, y, z)=\underbrace{\frac{e^{-2 \alpha p}}{2 \mu_{0}} \frac{\partial p}{\partial z}\left\{\frac{y(y-h)}{e^{-\alpha p}}+2 \ell^{2}\left[1-\frac{\operatorname{Cosh}\left(\frac{2 y-h}{2 \ell e^{-\frac{1}{2} \alpha p}}\right)}{\operatorname{Cosh}\left(\frac{h}{2 \ell e^{-\frac{1}{2} \alpha p}}\right)}\right]\right\}}_{\text {Hagen-Poiseuilleflow }} .
\end{aligned}
$$


In equation (31), $\dot{e}_{X}=\frac{d e_{X}}{d t}$ and $\dot{e}_{Y}=\frac{d e_{Y}}{d t}$ are the Cartesian components of the journal (crankpin) center velocities in $X$ - and $Y$-directions, respectively.

\section{Results and discussion}

\subsection{Computation procedure}

Based on the analysis described in the present paper, a computational code in MS-Fortran 90 was developed to study the isothermal elasto-hydro-dynamic (IEHD) behavior of layered connecting-rod big-end bearings lubricated with piezo-viscous fluids with couple-stress.

The prediction of instantaneous position of the shaft (crank pin) within the bush (big-end bearing) requires the solution of an inverse problem throughout the thermodynamic cycle of a reciprocating engine. In summary, the procedure of calculation needs the following five steps:

Step 1: From a position of the shaft center $\left(e_{X}, e_{Y}\right)$, we calculate the film thickness $h$ and the corresponding pressure $p$.

Step 2: The hydrodynamic load $W$ is calculated by integrating the pressure on the bearing surface.

Step 3: The calculated load is then compared with the applied load $F$ : if the calculated load is different from the applied load, we correct the position of the shaft, e.g. by the iterative Newton-Raphson method, and we restart the calculation.

Step 4: The iterative process is pursued until convergence: the center position of the shaft inside the bearing as well as the hydrodynamic characteristics of bearing are thus determined at each time $t$.

Step 5: The load cycle is repeated several times until two successive load cycles give identical shaft orbits.

The computed results include bearing center orbits, variations of the minimum film thickness, the peak pressure, the power loss and the side leakage flow versus the crank rotation angle $\theta_{2}$.

In this section, the couple-stress and the piezo-viscous effects in the ungrooved connecting-rod big-end bearing with thin elastic liner of the Ruston and Hornsby 6 VEB-X MK III four-stroke marine diesel engine are investigated. This particular connecting-rod bearing is the most analyzed bearing in the technical literature [29].

The polar and Cartesian diagrams of the dynamic load applied by the crankpin on the big end bearing of $0.127 \mathrm{~m}$ width during one engine cycle are presented graphically in Figure 2. The load data expressed in the mobile frame related to connecting-rod are reported in Table 1 for crank step $\triangle \theta_{2}=10^{\circ}$. These data are interpolated using cubic splines for each $1^{\circ}$ in order to ensure an accurate solution.

The peak load is about $208 \mathrm{kN}$ occurring at $\theta_{2}=10^{\circ}$ after top dead center (ATDC). For a four-stroke engine, there are $720^{\circ}$ crank angles in one engine cycle corresponding to two complete rotations of crankshaft. The time step used in the analysis being $1^{\circ}$ crank angle. So, there are 720 time steps or parts in one engine cycle, viz. $n$ steps $=720$.
Input parameters of engine, layered big-end bearing and the properties of the motor oil ISO VG 100 used in this investigation are reported in Tables $2-4$.

To analyze big-end bearing, which has a $360^{\circ}$ circumferential oil supply groove of $0.0127 \mathrm{~m}$ width machined at its mid-section, we model it by treating each half of the bearing land as a single bearing and assuming that the magnitude of the supply pressure was negligible, i.e. $p_{s}=0$. By exploiting symmetry, it was only necessary to analyze one half of the bearing land of $0.057 \mathrm{~m}$ width subjected to half loading. So, the load data given in Table 1 must be halved.

\subsection{Validation}

In order to verify the proposed method of solution, the specific case chosen is also the connecting-rod big-end bearing of the Ruston and Hornsby engine with and without a full circumferential groove.

In Figure 3, we compare the results obtained in the frame related to the connecting-rod $\left(X_{3}, Y_{3}\right)$ by the current method of solution based on the damped Newton-Raphson algorithm and the subrelaxed successive substitutions method with those calculated by a separate computer program using the mobility method of Booker described in details in reference [16]. The calculations were performed in isothermal regime for both grooved and ungrooved bearings with stiff liner using a Newtonian fluid of dynamic viscosity $\mu_{0}=15 \mathrm{mPa} \cdot \mathrm{s}$ as lubricant.

Table 5 gives another check for the correctness of the algorithm and the computer program by comparing the predicted values of the minimum oil film thickness and maximum film pressure with some results from the literature for both grooved (full circumferential groove) and ungrooved connecting-rod bearings [31-35].

Good agreement is observed and we may conclude that the method of solution used in the present analysis is validated for a rigid bearing lubricated with isoviscous Newtonian fluids and operating under isothermal conditions. Note that the discrepancies between the results may be caused partly by the effect of supply pressure. Indeed, our calculations were performed for the grooved bearing configuration by setting the supply pressure in the feeding groove at zero instead of $p_{s}=0.294 \mathrm{MPa}$ as stated in reference [35].

\subsection{Parametric study}

Three different coated bearing configurations of the ungrooved Hornsby \& Ruston connecting-rod big-end bearing are used for the isothermal analysis in order to put in evidence the effects of the piezo-viscous and the presence of couple-stresses in the lube oil on the dynamic responses of these bearings. In this analysis, the dynamic responses of a traditional bearing with a stiff liner of $2 \mathrm{~mm}$ thickness are calculated and compared with those obtained for bearings with compliant liners made from white metal (Babbitt) and polymer materials. Properties of the oil sample and elastic characteristics of the bearing liner materials are reported in Tables 3 and 4 . 
(a) Polar representation

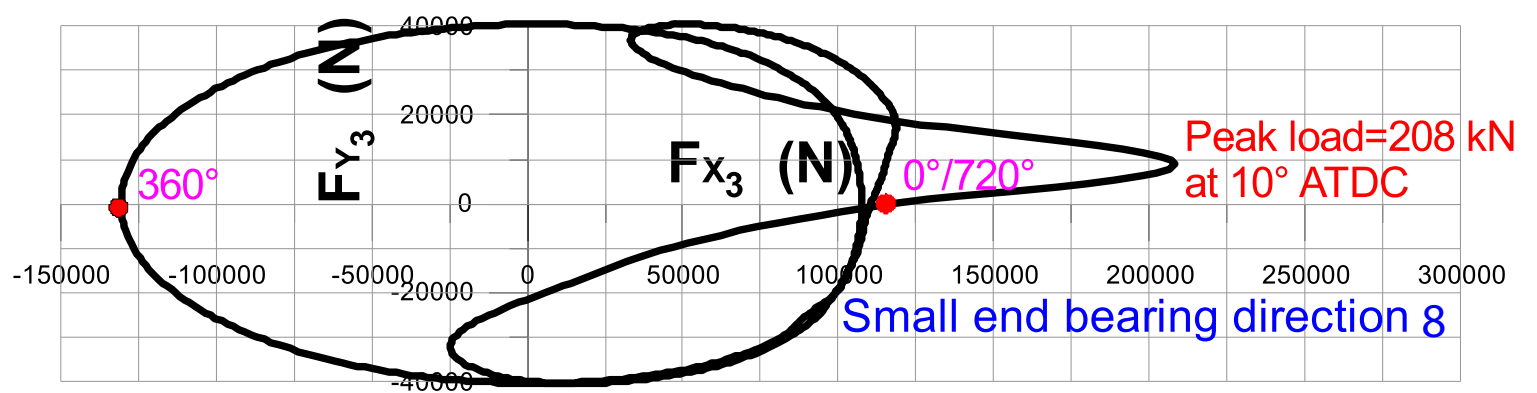

(b) Cartesian representation

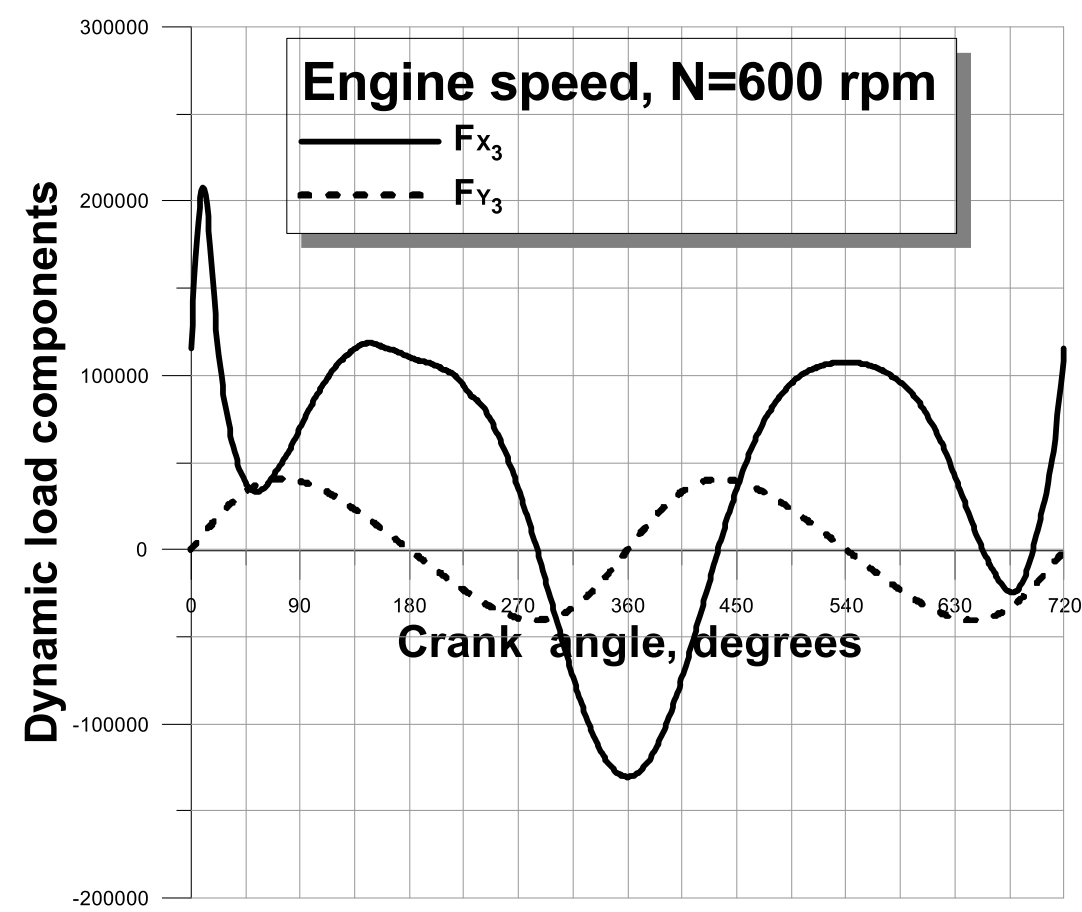

Fig. 2. Dynamic loading on the Ruston and Hornsby 6 VEB-X connecting-rod big-end bearing including gas and inertia forces.

\subsection{Couple-stress effects}

In Figure 4, three stationary journal (crankpin) orbits are plotted in polar diagrams corresponding to the three following configurations: a traditional bearing with stiff liner, which is considered as rigid in solid line, and two bearings with different liner materials (white metal, which is a compressible material, and polymer (PEHD), which is an incompressible material) in dash and dash-dot lines, respectively. The clearance circle $e / C=1$ is also plotted with dash line. For each bearing, the lubricant is considered as a piezo-viscous fluid $\left(\alpha=20 \mathrm{GPa}^{-1}\right)$, and the load cycle is repeated several times until two successive load cycles give identical shaft or journal orbits.

It is observed that the crankpin center orbits for both Newtonian and non-Newtonian lubricants have similar shapes even though the bearing is compliant. But the couple-stresses produce more contracted trajectories of the shaft center, which result in higher minimum oil film thicknesses as depicted in Figures 5 and 6 .

Although the minimum film thickness is sensitively increased by the presence of couple-stresses, the maximum film pressure is not really affected for both stiff and compliant bearings as shown in Figures 7a and 7b. It is well known that taking into account couple-stress effects leads to a pressure distribution increase.

For the compliant bearing with a Babbitt liner, the average values of minimum film thickness and maximum film pressure obtained over the cycle are, respectively, about $9.82 \mu \mathrm{m}$ and $22.32 \mathrm{MPa}$ for the Newtonian oil and $27.61 \mu \mathrm{m}$ and $20.39 \mathrm{MPa}$ for the oil blended with polymers 
Table 1. Connecting-rod bearing loads at $N=600 \mathrm{rpm}$ adapted from references [18,29].

\begin{tabular}{|c|c|c|c|c|c|c|c|}
\hline \multirow{2}{*}{$\begin{array}{l}\theta_{2}(\text { deg. }) \\
0\end{array}$} & \multirow{2}{*}{$\begin{array}{l}F_{X_{3}},(\mathrm{~N}) \\
115336.60\end{array}$} & \multirow{2}{*}{$\begin{array}{l}F_{Y_{3}},(\mathrm{~N}) \\
0.000000\end{array}$} & \multirow{2}{*}{$\begin{array}{l}\psi(\text { deg. })=\operatorname{atan}\left(\frac{F_{Y_{3}}}{F_{X_{3}}}\right) \\
0 .\end{array}$} & \multicolumn{2}{|c|}{$\theta_{2}($ deg. $) F_{X_{3}},(\mathrm{~N})$} & \multirow{2}{*}{$\begin{array}{r}F_{Y_{3}},(\mathrm{~N}) \\
8784.80\end{array}$} & \multirow{2}{*}{$\begin{array}{l}\psi(\text { deg. }) \\
176.05\end{array}$} \\
\hline & & & & 370 & -127301.80 & & \\
\hline 10 & 207899.50 & 8784.80 & 2.42 & 380 & -118183.40 & 17107.01 & 171.76 \\
\hline 20 & 134996.80 & 17107.01 & 7.22 & 390 & -103593.90 & 24539.62 & 166.67 \\
\hline 30 & 76594.56 & 24539.62 & 17.76 & 400 & -84378.56 & 30744.58 & 159.98 \\
\hline 40 & 46481.60 & 30744.58 & 33.48 & 410 & -61738.24 & 35495.04 & 150.10 \\
\hline 50 & 34343.01 & 35495.04 & 45.95 & 420 & -37020.70 & 38670.91 & 133.75 \\
\hline 60 & 35148.09 & 38670.91 & 47.73 & 430 & -11720.48 & 40276.64 & 106.22 \\
\hline 70 & 44524.48 & 40276.64 & 42.13 & 440 & 12699.04 & 40401.18 & 72.55 \\
\hline 80 & 55511.04 & 40401.18 & 36.04 & 450 & 35014.66 & 39222.46 & 48.24 \\
\hline 90 & 69967.04 & 39222.46 & 29.27 & 460 & 54354.56 & 36936.19 & 34.20 \\
\hline 100 & 83755.84 & 36936.19 & 23.80 & 470 & 70233.92 & 33755.87 & 25.67 \\
\hline 110 & 95809.92 & 33755.87 & 19.41 & 480 & 82643.84 & 29890.56 & 19.88 \\
\hline 120 & 105506.60 & 29890.56 & 15.82 & 490 & 91895.68 & 25509.28 & 15.51 \\
\hline 130 & 112401.00 & 25509.28 & 12.78 & 500 & 98434.24 & 20763.26 & 11.91 \\
\hline 140 & 117382.70 & 20763.26 & 10.03 & 510 & 102837.80 & 15759.26 & 8.71 \\
\hline 150 & 118361.30 & 15759.26 & 7.58 & 520 & 105551.00 & 10586.24 & 5.73 \\
\hline 160 & 115870.40 & 10586.24 & 5.22 & 530 & 107018.90 & 5315.36 & 2.84 \\
\hline 170 & 113646.40 & 5315.36 & 2.67 & 540 & 107508.20 & 0.000000 & 0. \\
\hline 180 & 110443.80 & 0.000000 & 0. & 550 & 107018.90 & -5315.36 & 357.16 \\
\hline 190 & 108130.90 & -5315.36 & 357.2 & 560 & 105551.00 & -10586.24 & 354.27 \\
\hline 200 & 106307.20 & -10586.24 & 354.3 & 570 & 102837.80 & -15759.26 & 351.29 \\
\hline 210 & 102837.80 & -15759.26 & 351.3 & 580 & 98434.24 & -20763.26 & 348.09 \\
\hline 220 & 98434.24 & -20763.26 & 348.1 & 590 & 93007.68 & -25509.28 & 344.66 \\
\hline 230 & 89253.57 & -25509.28 & 344.05 & 600 & 84912.32 & -29890.56 & 340.61 \\
\hline 240 & 82643.84 & -29890.56 & 340.12 & 610 & 73258.56 & -33755.87 & 335.26 \\
\hline 250 & 70233.92 & -33755.87 & 334.33 & 620 & 59247.36 & -36936.19 & 328.06 \\
\hline 260 & 54354.56 & -36936.19 & 325.80 & 630 & 41811.20 & -39222.46 & 316.83 \\
\hline 270 & 35014.66 & -39222.46 & 311.76 & 640 & 23267.49 & -40401.18 & 299.94 \\
\hline 280 & 12699.04 & -40401.18 & 287.44 & 650 & 4087.712 & -40276.64 & 275.79 \\
\hline 290 & -11720.48 & -40276.64 & 253.78 & 660 & -10399.42 & -38670.91 & 254.95 \\
\hline 300 & -37020.70 & -38670.91 & 226.25 & 670 & -21443.81 & -35495.04 & 238.87 \\
\hline 310 & -61738.24 & -35495.04 & 209.89 & 680 & -23872.42 & -30744.58 & 232.18 \\
\hline 320 & -84378.56 & -30744.58 & 200.02 & 690 & -10270.43 & -24539.62 & 247.29 \\
\hline 330 & -103593.90 & -24539.62 & 193.32 & 700 & 17142.59 & -17107.01 & 315.06 \\
\hline 340 & -118183.40 & -17107.01 & 188.24 & 710 & 51774.72 & -8784.80 & 350.37 \\
\hline 350 & -127301.80 & -8784.80 & 183.94 & 720 & 115336.60 & 0.000000 & 0. \\
\hline 360 & -130370.90 & 0.000000 & 189.00 & & & & \\
\hline
\end{tabular}

Table 2. Diesel Ruston and Hornsby 6 VEB engine parameters data.

\begin{tabular}{lll}
\hline Parameter, symbol & Unit & Value \\
\hline Engine speed, $N$ & rpm & 600 \\
Crankshaft arm length (crank throw), $\ell_{2}$ & $\mathrm{~m}$ & 0.184 \\
Connecting-rod length, $\ell_{3}$ & $\mathrm{~m}$ & 0.782 \\
Engine cycle (crank angle) & degrees & 720 \\
\hline
\end{tabular}


Table 3. Input parameters (geometric characteristics and operating conditions) used to study the performance characteristics of layered connecting-rod bearing.

\begin{tabular}{lll}
\hline Parameter, Symbol & Unit & Value \\
\hline Bearing diameter, $D$ & $\mathrm{~m}$ & 0.2032 \\
Bearing length, $L$ & $\mathrm{~m}$ & 0.127 \\
Radial clearance, $C$ & $\mathrm{~m}$ & $82.55 \times 10^{-6}$ \\
Circumferential groove width & $\mathrm{m}$ & 0.0127 \\
Circumferential groove angular amplitude & degrees & 360 \\
Ambient and cavitation pressures, $p_{\text {atm }}, p_{\text {cav }}$ & $\mathrm{Pa}$ & 0.0 \\
Supply pressure, $p_{s}$ & $\mathrm{~Pa}$ & 0.0 \\
Young's modulus of bearing liner, $E$ at $T=20^{\circ} \mathrm{C}(68 \mathrm{~F})[30]$ & $\mathrm{GPa}$ & 29 \\
- Babbitt, lead base white metal & & 0.9 \\
- Polyethylene high density & & 0.33 \\
Poisson's ratio of bearing liner, $\sigma$ at $T=20^{\circ} \mathrm{C}(68 \mathrm{~F})[30]$ & - & 0.35 \\
- Babbitt, lead base white metal & & $2 \times 10^{-3}$ \\
- Polyethylene high density & $\mathrm{m}$ &
\end{tabular}

Table 4. Rheological and physical properties of the motor oil ISO VG 100 under study.

\begin{tabular}{lll}
\hline Parameter, symbol & Unit & Value \\
\hline Couple-stress parameter at constant temperature, $\eta$ & $\mathrm{N} \cdot \mathrm{s}^{-1}$ & $10^{-11}$ \\
Viscosity-pressure coefficient at constant temperature, $\alpha$ (first Barus' parameter) & $\mathrm{Pa}^{-1}$ & $2 \times 10^{-8}$ \\
Dynamic viscosity at $p=0$ and a constant temperature, $\mu_{0}$ (second Barus' parameter) & $\mathrm{Pa} \cdot \mathrm{s}$ & $15 \times 10^{-3}$ \\
\hline
\end{tabular}

(a) Steady-state orbits for un-grooved bearing

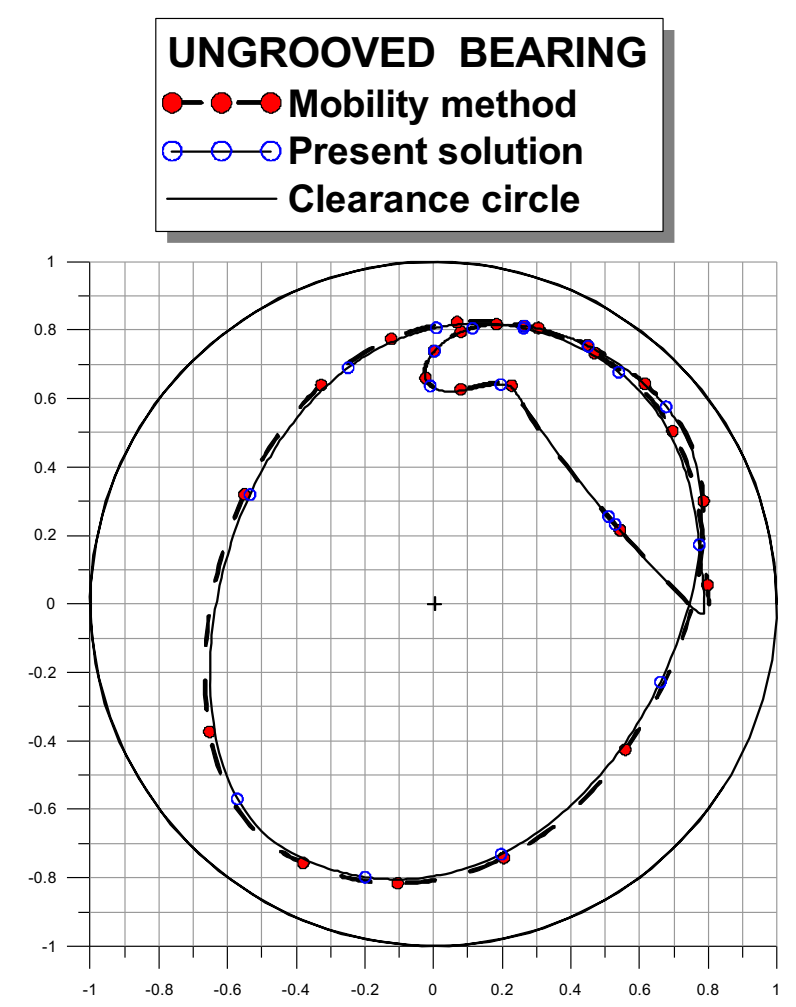

(b) Steady-state orbits for grooved bearing

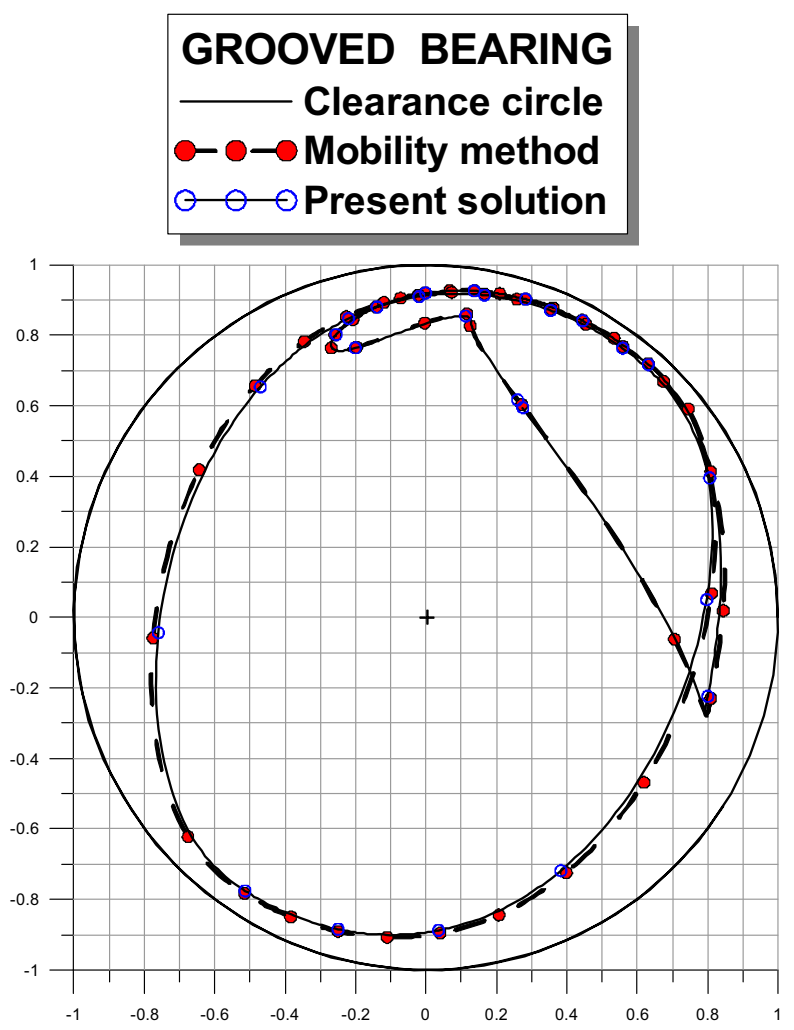

Fig. 3. Comparison of predicted crank pin center cyclic path for both grooved and ungrooved Ruston and Hornsby 6 VEB connectingrod bearings determined after two load cycles. 
Table 5. Comparison of numerical results obtained in the present analysis with those provided by literature.

\begin{tabular}{|c|c|c|c|c|c|c|c|}
\hline & \multicolumn{3}{|c|}{ Ungrooved bearing } & \multicolumn{4}{|c|}{ Grooved bearing } \\
\hline & $\begin{array}{l}\text { Present } \\
\text { analysis }\end{array}$ & $\begin{array}{l}\text { Goenka and } \\
\text { Paranjpe } \\
\text { [31] }\end{array}$ & $\begin{array}{l}\text { Vincent and } \\
\text { Maspeyrot } \\
{[33]}\end{array}$ & $\begin{array}{l}\text { Present } \\
\text { analysis }\end{array}$ & $\begin{array}{l}\text { Goenka } \\
{[34,35]}\end{array}$ & $\begin{array}{l}\text { Vijayaraghavan } \\
{[32]}\end{array}$ & $\begin{array}{l}\text { Vincent and } \\
\text { Maspeyrot } \\
{[33]}\end{array}$ \\
\hline$h_{\min }(\mu \mathrm{m})$ & 9.16 at $\theta_{2}=280^{\circ}$ & 8.78 & 8.74 & 3.74 at $\theta_{2}=272^{\circ}$ & 3.47 & 3.60 & 4.03 \\
\hline$p_{\max }(\mathrm{MPa})$ & 21.06 at $\theta_{2}=11^{\circ}$ & - & - & 34.59 at $\theta_{2}=11^{\circ}$ & 34.40 & - & - \\
\hline
\end{tabular}

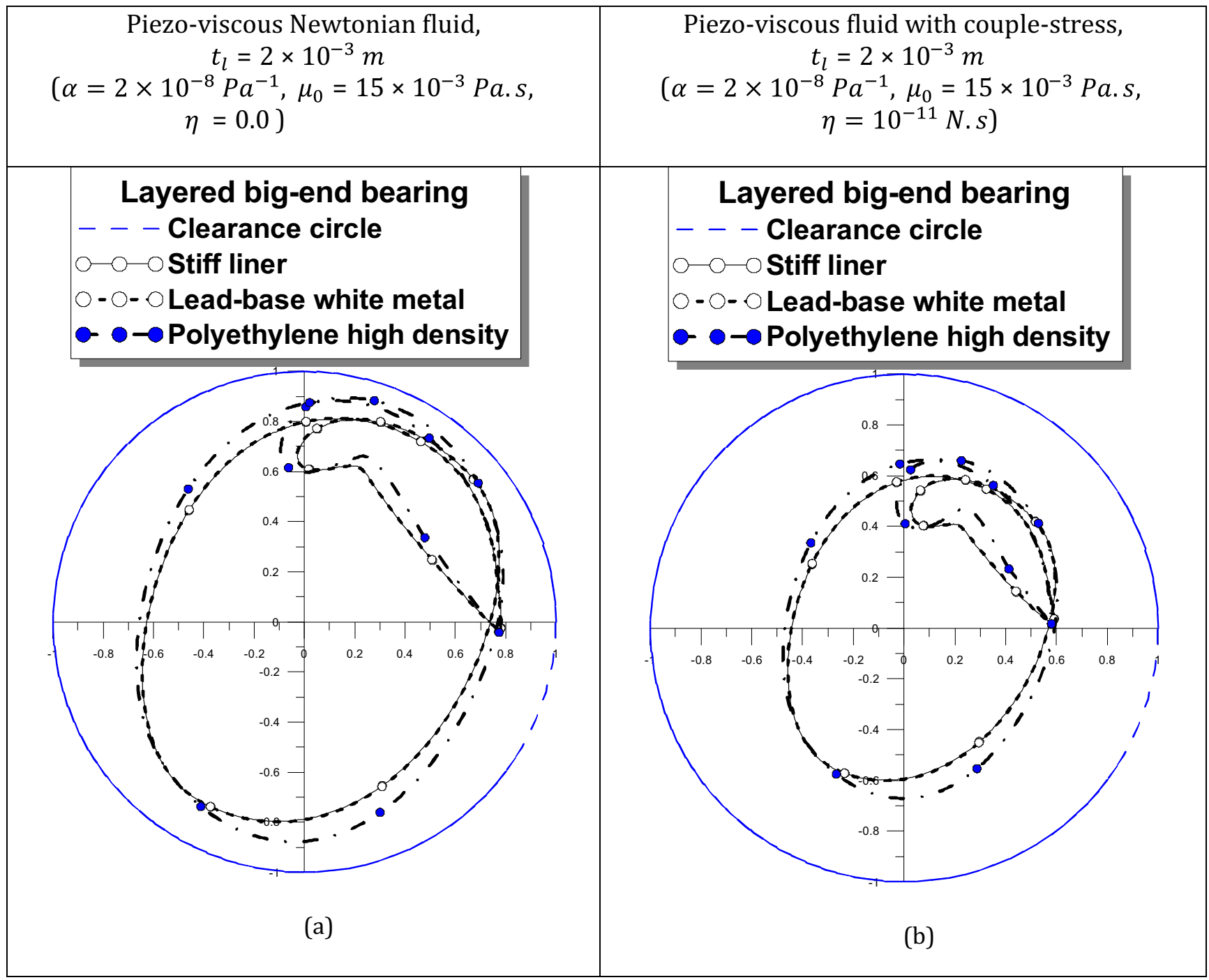

Fig. 4. Stationary crankpin center orbits for a complete engine cycle giving two crankshaft rotations.

(couple-stress fluid model). Hence, the couple-stresses result in an important increase of the minimum film thickness by about $180 \%$ and a very slight drop in peak film pressure by about $9 \%$.

Likewise, for the compliant bearing with a liner made of polymer (PEHD), which is a more compliant material characterized by a lower elasticity modulus $(E=0.9 \mathrm{GPa})$, the couple-stresses lead to a much more important increase of the minimum film thickness by about $317 \%$ and a much slighter drop in peak film pressure by about $6 \%$ even though the minimum film thickness and the peak film pressure are much lower than those obtained in the previous bearing case, i.e. the compliant bearing with a liner made of white metal (Babbitt). 


\begin{tabular}{|c|c|}
\hline $\begin{array}{c}\text { Piezo-viscous Newtonian fluid, } \\
t_{l}=2 \times 10^{-3} \mathrm{~m} \\
\left(\alpha=2 \times 10^{-8} \mathrm{~Pa}^{-1}, \mu_{0}=15 \times 10^{-3} \mathrm{~Pa} . \mathrm{s}\right. \\
\eta=0.0)\end{array}$ & $\begin{array}{c}\text { Piezo-viscous fluid with couple-stress, } \\
t_{l}=2 \times 10^{-3} \mathrm{~m} \\
\left(\alpha=2 \times 10^{-8} \mathrm{~Pa}^{-1}, \mu_{0}=15 \times 10^{-3} \mathrm{~Pa} . \mathrm{s},\right. \\
\left.\eta=10^{-11} \mathrm{~N} . \mathrm{s}\right)\end{array}$ \\
\hline $\begin{array}{l}\text { Layered big-end bearing } \\
\circ-\infty-\bigcirc \text { Stiff liner } \\
0-\bigcirc-\bigcirc \text { Lead-base white metal } \\
\bullet-\bullet-\bullet \text { Polyethylene high density }\end{array}$ & $\begin{array}{l}\text { Layered big-end bearing } \\
\circ-\circ-\circ \text { Stiff liner } \\
\circ-\circ-\circ \text { Lead-base white metal } \\
-\bullet-\bullet \text { Polyethylene high density }\end{array}$ \\
\hline Crank angle, degrees & (b) \\
\hline
\end{tabular}

Fig. 5. Global minimum oil film thickness during the complete load cycle.

Table 6 summarizes the results obtained for the three different coated bearing configurations.

Figure 8 depicts the variation of side leakage flow and power loss versus crank angle for both Newtonian $(l=0)$ and non-Newtonian oils $(l / C=0.3)$. It is shown that for the same applied dynamic load, with Newtonian fluid we obtain higher side leakage flow and power loss when compared to couple-stress fluid.

For the compliant bearing with a Babbitt liner (Tab. 6), the mean values of side leakage flow and power loss for the Newtonian fluid are higher than those for the couple-stressfluid by about 40 and $36 \%$, respectively. Note that the peaks of side leakage flow and power loss occur at $\theta_{2}=10^{\circ}$ ATDC.

\subsection{Effects of bearing liner elasticity}

Stationary journal orbits of coated and uncoated (stiff) bearings calculated for both Newtonian and couple-stress lubricants are compared in Figure 4. As can be seen, the journal orbit of the bearing coated with the liner in white metal (Babbitt) is almost identical to that of the stiff bearing. Unlike, the journal orbit of the bearing coated with PEHD liner is significantly affected by the local deforma- tion of the bearing liner compared to the journal orbit of the bearing coated with liner in white metal characterized by an elasticity modulus greater than that of the PEHD.

From Figures 5 to 7 , which describe the history of the minimum oil film thickness and the peak oil film hydrodynamic pressure predicted for both Newtonian and couple-stress fluids, it can be seen that there are significant differences throughout the cycle in the minimum film thickness and in the peak film pressure between the most compliant bearing, i.e. the bearing with a liner in PEHD and the bearing with a liner in white metal.

As indicated in Table 6, the least minimum oil film thickness in one engine cycle obtained for the piezo-viscous Newtonian case is $9.825 \mu \mathrm{m}$ for the compliant bearing with a liner in white metal and $5.88 \mu \mathrm{m}$ for the compliant bearing with a liner in PEHD (about $40 \%$ variation), and the largest peak oil film hydrodynamic pressure is about $22 \mathrm{MPa}$ for the compliant bearing with a liner in white metal (Babbitt) and $16 \mathrm{MPa}$ for the compliant bearing with a liner in PEHD (about 27\% variation). However, the least minimum oil film thickness in one engine cycle calculated for the piezoviscous fluid with couple-stresses is $27.61 \mu \mathrm{m}$ for the compliant bearing with a liner in white metal and $24.52 \mu \mathrm{m}$ for the compliant bearing with a liner in PEHD (i.e. about $11 \%$ 


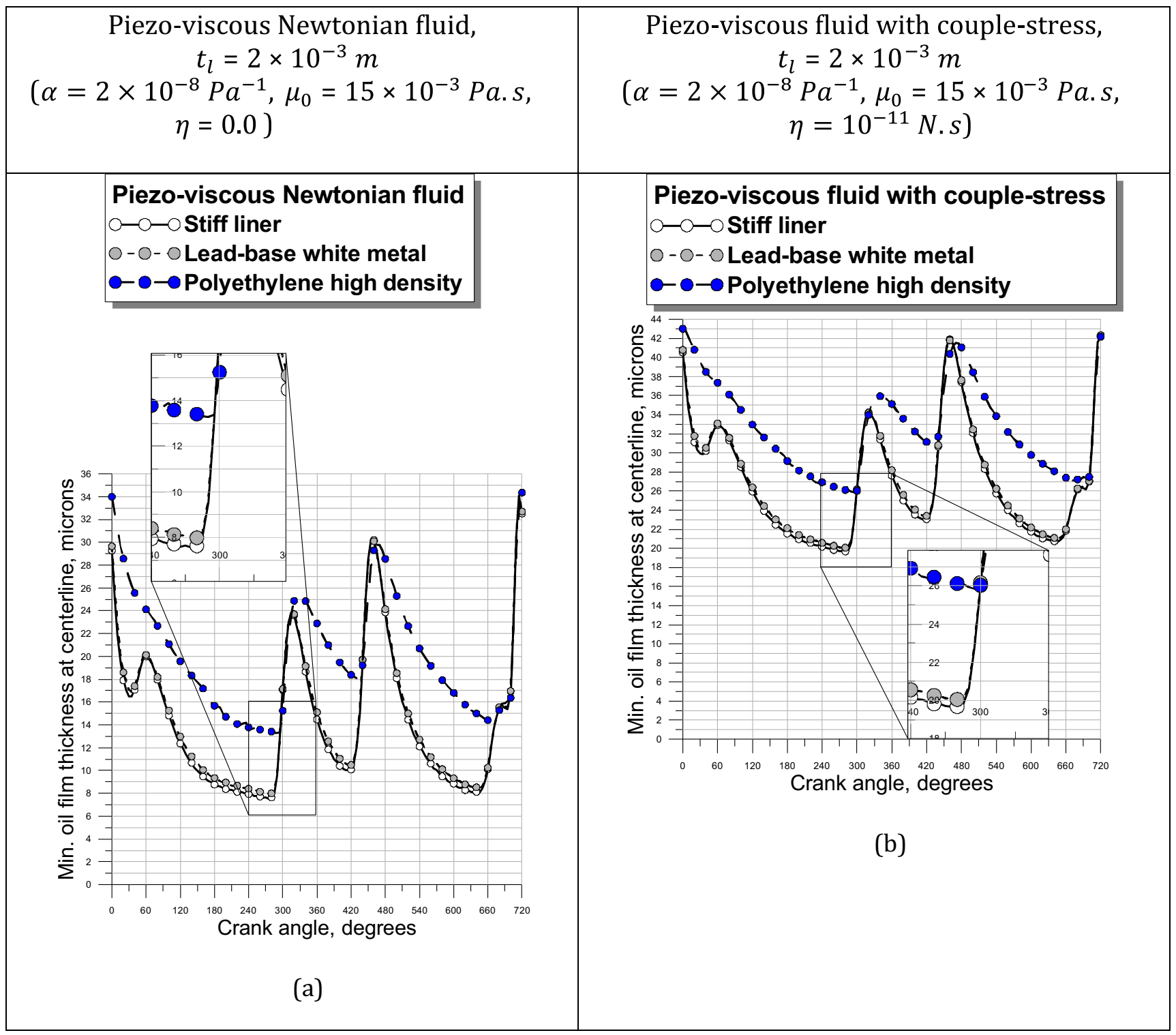

Fig. 6. Minimum oil film thickness calculated at the bearing centerline during the complete load cycle.

variation, which is quite very small than that of the Newtonian case), and the largest peak oil film hydrodynamic pressure is about $20 \mathrm{MPa}$ for the compliant bearing with a liner in white metal and $15 \mathrm{MPa}$ for the compliant bearing with a liner in PEHD (i.e. about $25 \%$ variation), which is almost identical to that of the Newtonian case.

From the same figures, it can also be seen that the global least minimum oil film thicknesses calculated for the bearing with a liner in white metal (i.e. the second bearing configuration) and the bearing with a liner in PEHD (third bearing configuration) occurs at different values of the crankshaft rotation angle due to the elasticity effect of the bearing liner, whereas the peak oil film hydrodynamic pressure always is present at the same crank angle, i.e. in the vicinity of $\theta_{2}=10^{\circ}$ ATDC for which the peak load appears as depicted in Figure 2. Note that the global minimum film thickness arises at the layered bearing edges and it is always lower than that calculated in the midsection of the compliant bearing.

Figure 8 also compares the variations of side leakage flow and power loss with crank angle for the three bearings configurations (stiff and compliant bearings). The leakage flow as well as the power loss show little difference over the cycle for both Newtonian and non-Newtonian cases. Note that the power loss is calculated considering only the area with a full film. It can be concluded that there is no significant effect of the bearing compliance on the side leakage flow and the power loss. These results agree qualitatively with those obtained by Mc Ivor and Fenner [36] when the global deformations of the whole structure of the Ruston and Hornsby connecting-rod big-end bearing are considered in their finite element analysis. 


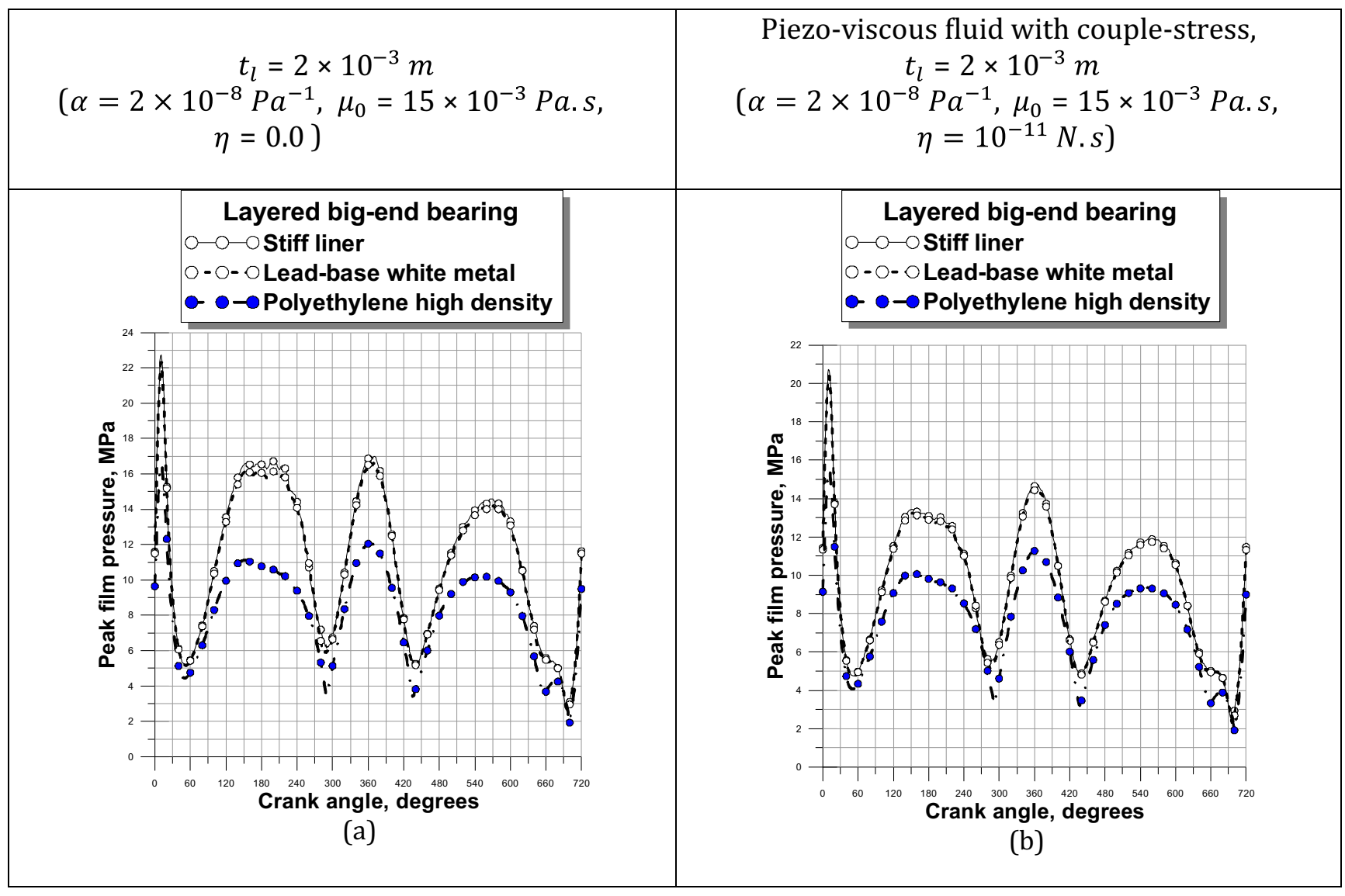

Fig. 7. Maximum oil film pressure during the complete load cycle.

Table 6. Comparison of hydrodynamic characteristics for isothermal analysis.

\begin{tabular}{lllllll}
\hline & & $h_{\min }, \mu \mathrm{m}$ & $p_{\max }, \mathrm{MPa}$ & $\varepsilon_{\max }$ & $\begin{array}{l}\left\langle Q_{z}\right\rangle, \mathrm{cm}^{3} / \mathrm{s} \\
\text { or cc/s }\end{array}$ & $\langle\mathcal{P}\rangle, W$ \\
\hline$\alpha=2 \times 10^{-8} \mathrm{~Pa}^{-1}$ & $1^{\mathrm{a}}$ & 9.825 & 22.32 & 0.881 & 47.5 & 1010 \\
$\mu_{0}=15 \times 10^{-3} \mathrm{~Pa} \cdot \mathrm{s}$ & $2^{\mathrm{b}}$ & 5.88 & 16.55 & 0.93 & 48. & 998 \\
$\eta=0$ & $3^{\mathrm{c}}$ & 9.81 & 22.72 & 0.881 & 47.5 & 1012 \\
$\alpha=2 \times 10^{-8} \mathrm{~Pa}^{-1}$ & $1^{\mathrm{a}}$ & 27.61 & 20.39 & 0.666 & 33.9 & 743 \\
$\mu_{0}=15 \times 10^{-3} \mathrm{~Pa} \cdot \mathrm{s}$ & $2^{\mathrm{b}}$ & 24.52 & 15.51 & 0.70 & 34. & 759 \\
$\eta=10^{-11} \mathrm{~N} \cdot \mathrm{s}$ & $3^{\mathrm{c}}$ & 27.55 & 20.73 & 0.67 & 33.9 & 743 \\
\hline
\end{tabular}

${ }^{a}$ Babbitt, lead-base white metal;

b Polyethylene high density (PEHD);

${ }^{\mathrm{c}}$ Stiff liner.

Due to the bearing liner deformation, the gap between the deformed bearing surface and the shaft is geometrically different than that between the rigid bearing surface and the shaft. Accordingly, the hydrodynamic pressure profile is also different for the two bearing configurations. Figure 9 shows the hydrodynamic pressure profiles along the centerline calculated for the bearing with a liner in white metal and the bearing with a liner in PEHD for some crank rotation angles. As expected, one peak pressure occurs in the circumferential direction of the bearings since only the local deformations are considered. Besides, the maximum hydrodynamic pressure for the most compliant bearing (bearing with PEHD liner) is lower than that obtained in the case of the bearing with a liner in white metal having a greater elasticity. 


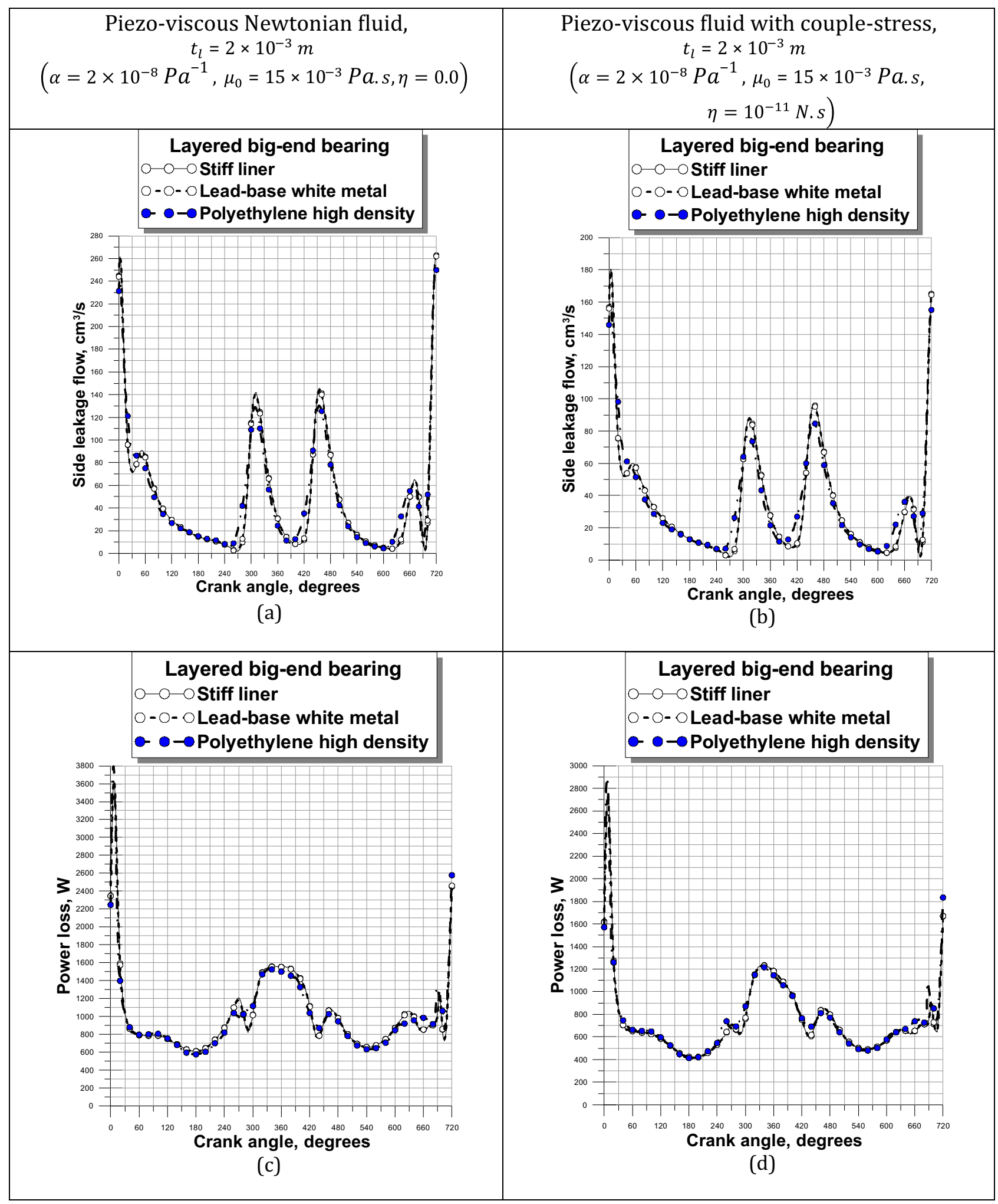

Fig. 8. Side leakage flow and power loss during the complete load cycle. 


\begin{tabular}{|c|c|}
\hline $\begin{array}{l}\text { Piezo-viscous Newtonian fluid, } t_{l}=2 \times 10^{-3} \mathrm{~m} \\
\quad\left(\alpha=2 \times 10^{-8} \mathrm{~Pa}^{-1}, \mu_{0}=15 \times 10^{-3} \mathrm{~Pa} . \mathrm{s}, \eta=0.0\right)\end{array}$ & $\begin{array}{l}\text { Piezo-viscous fluid with couple-stress, } t_{l}=2 \times 10^{-3} \mathrm{~m} \\
\left(\alpha=2 \times 10^{-8} \mathrm{~Pa}^{-1}, \mu_{0}=15 \times 10^{-3} \mathrm{~Pa} . \mathrm{s}\right. \\
\left.\eta \eta 10^{-11} \mathrm{~N} . \mathrm{s}\right)\end{array}$ \\
\hline Layered big-end bearing & $\left.\begin{array}{c}\text { Layered big-end bearing } \\
0-0-0 \text { Lead-base white metal } \\
0 \rightarrow 0 \text { - Polyethylene high density }\end{array}\right]$ \\
\hline 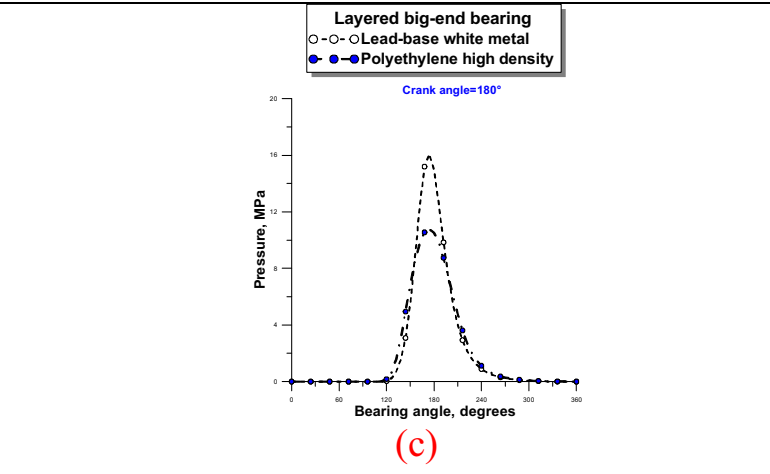 & Crank angle=180 \\
\hline Crank angle=360" & Crank angle=360" dessity \\
\hline Cayered big-end bearing & Crenk angle=540" \\
\hline
\end{tabular}

Fig. 9. Hydrodynamic pressure profiles in the mid-section of the bearing for some crank angles $\theta_{2}$. 


\section{Concluding comments}

The combined effects of couple-stresses and piezoviscosity in dynamically loaded connecting-rod big-end bearings with thin elastic liners under isothermal conditions have been undertaken. The motor oil used for lubricating such bearings was modeled as a nonNewtonian couple-stress fluid in order to take into account the couple-stresses in addition to the surface forces due to the presence of various polymer additives. We showed that this fluid model is characterized by a skew symmetric stress tensor which comprises two physical properties $\mu$ and $\eta$ denoting the classical dynamic viscosity and the additional coefficient that specifies the couple-stress character of the fluid, respectively. To these two coefficients, we have added a third one denoted $\alpha$ to take into account the piezo-viscosity effect. As the piezoviscosity $\alpha$ is independent of temperature in the present work, the combined effects of couple-stresses and piezoviscosity on the dynamic response of three layered connecting-rod bearing configurations were only investigated using the isothermal assumption. Moreover, an improved and relaxed iterative Newton-Raphson method has been proposed for solving the equilibrium equations in order to determine the trajectories of the crankpin center within layered bearings.

The conclusions are as follows:

1. The pressure equation derived in this paper is more general than the classical Reynolds equation for the study of dynamically loaded bearings with elastic layers using piezo-viscous fluids with couple-stress as lubricants.

2. With the same applied dynamic loads, the couple-stress fluids yield higher least minimum oil film thickness, and more contracted orbits than Newtonian fluids.

3. The elastic deformations effects result in an expansion of the orbit and a decrease of the maximum hydrodynamic pressure especially for layered bearings with lowelasticity modulus coatings (e.g. bearing with PEHD liner).

4. For the cases investigated, the couple-stress effects are more significant than the piezo-viscous effects.

\section{Nomenclature}

$\begin{array}{ll}C & \text { Bearing radial clearance, } \mathrm{m} \\ \mathcal{C} & \text { Scalar compliance operator, }{ }^{m} /{ }_{P} a \\ E & \text { Young's modulus of the bearing-liner, } \\ & \text { Pa } \\ F_{X}, F_{Y} & \text { Eccentricity, }=\sqrt{e_{X}^{2}+e_{Y}^{2}}, \mathrm{~m} \\ F & \text { Applied load components, } \mathrm{N} \\ & \text { Dynamic load applied on the big-end } \\ e_{X}, e_{Y} & \text { bearing, }=\sqrt{F_{X}^{2}+F_{Y}^{2}}, \mathrm{~N} \\ h & \text { Displacement components of the shaft } \\ L & \text { (crankpin) center, m } \\ & \text { Oil-film thickness, m } \\ & \text { Length of bearing, } \mathrm{m}\end{array}$

$l$

$N$

$p$

$p_{\max }$

$p_{s}$

$p_{\text {atm }}$

$p_{\text {cav }}$

$Q_{z}$

$R$

$T$

$t$

$\Delta t$

$t_{1}$

$k$

$\ell_{2}$

$\ell_{3}$

$\left(\mathrm{O}_{b}, X_{3}, Y_{3}\right)$ or $\left(\mathrm{O}_{b}, X, Y\right)$

$\mathcal{P}$

$\mathcal{P}_{\text {shear }}$

$\mathcal{P}_{\text {squeeze }}$

$z$

$v_{i}$

$\alpha$

$\varepsilon$

$\eta$

$\mu$

$\nu$

$\sigma$

$C_{p}$

$\theta$

$\theta_{2}$

$\theta_{3}$

$\theta_{1}^{*}, \theta_{2}^{*}$

$\omega_{2}$

$\omega_{s}$

$\omega_{b}$

$\bar{\omega}$

$\psi$

$\rho$

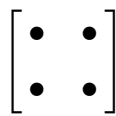

$\langle\bullet\rangle$
Characteristics length of polymer additives, $=\sqrt{\eta / \mu}, \mathrm{m}$

Rotational speed of engine (crankshaft), rpm

Oil film pressure, $\mathrm{Pa}$

Instantaneous maximum film pressure, $\mathrm{Pa}$

Supply pressure, $\mathrm{Pa}$

Ambient pressure, $\mathrm{Pa}$

Cavitation pressure, $\mathrm{Pa}$

Side leakage flow, $\mathrm{m}^{3} / \mathrm{s}$

Shaft radius, $m$

Temperature field in the fluid, $\mathrm{K}$

Time, s

Time increment, $\mathrm{s}$

Thickness of bearing-liner, $m$

Thermal conductivity of the fluid,

$\mathrm{W} / \mathrm{m} \cdot \mathrm{K}$

Crankshaft-arm length, m

Connecting-rod length, $\mathrm{m}$

Mobile frame related to the connectingrod

Total power loss, W

Shear power loss, W

Squeeze power loss, W

Axial coordinate measured from middle section plane of the bearing, $m$

Cartesian components of the velocity of fluid, $\mathrm{m} / \mathrm{s}$

Pressure-viscosity coefficient, $\mathrm{Pa}^{-1}$

Eccentricity ratio, $\varepsilon=\frac{e}{C}$

Material constant responsible for couple-stresses, $\mathrm{N} \cdot \mathrm{s}$

Absolute viscosity of lubricant, $\mathrm{Pa} \cdot \mathrm{s}$

Kinematic viscosity of lubricant, $\mathrm{m}^{2} / \mathrm{s}$ Poisson's ratio of the bearing-liner, Lubricant specific heat, $\mathrm{J} / \mathrm{kg} \cdot \mathrm{K}$

Bearing angle, rad

Crank angle, rad

Angle between $X_{1}$-axis related to engine block and connecting-rod, rad Instantaneous angular position of the start and the end of the pressure curve, respectively, rad

Angular velocity of the crankshaft, $=\frac{d \theta_{2}}{d t}, \operatorname{rad} / \mathrm{s}$

Angular velocity of shaft (crankpin), $\mathrm{rad} / \mathrm{s}$

Angular velocity of bearing, $=\frac{d \theta_{3}}{d t}, \mathrm{rad} / \mathrm{s}$ Average angular velocity of shaft and bearing, $=\frac{\omega_{s}+\omega_{b}}{2}, \mathrm{rad} / \mathrm{s}$

Angle between the direction of applied load $F$ and $X$-direction, rad

Mass density of lubricant, $\mathrm{kg} / \mathrm{m}^{3}$

Square matrix

Average quantity 
$\left\{\begin{array}{l}\bullet \\ \bullet\end{array}\right\}$

Column vector

$\left\{\begin{array}{l}\bullet \\ \bullet\end{array}\right\}^{T}$

Line vector where the superscript $T$ means the transpose

\section{Abbreviations}

ATDC : After top dead center

EHD : Elasto-hydro-dynamic

IEHD : Isothermal elasto-hydro-dynamic

GS : Gauss-Seidel

ISO : International Organization for Standardization

PEHD : Poly-ethylene high density

rpm : Revolution per minute

VG : Viscosity grade

VI : Viscosity index of lubricating oil

nsteps : Number of time steps in a load cycle

\section{References}

[1] J. Briant, Comportement rhéologique des lubrifiants avec additif de VI, Journée d'études sur l'influence du lubrifiant dans les pertes par frottement et l'usure dans les moteurs, Institut Français du Pétrole (IFP), 22 novembre1978, Collection Colloques et Séminaires 33, Editions TechnipParis

[2] A.S. Lodge, Elastic liquids, Academic Press, London, 1964

[3] R.C. Rosenberg, A method for determining the influence of multigrad oils on journal bearing performance, SAE Trans. 82 (1973) 730483

[4] R.C. Rosenberg, The influence of polymer additives on journal bearings performance, SAE, Paper 7506 92, 1975

[5] M. Robin, Etude de la lubrification des paliers de longueur finie: Influence des additifs de viscosité, Thèse de doctorat, Janvier 1978, Editions Technip

[6] D.R. Oliver, Load enhancement effects due to polymer thickening in a short model journal bearings, J. NonNewtonian Fluid Mech. 30 (1988) 185-196

[7] W. Scott, P. Suntiwattana, Effect of oil additives on the performance of a wet friction clutch material, Wear 181-183 (1995) 850-855

[8] V.K. Stokes, Couple-stresses in fluids, Phys. Fluids 9 (1966) 1709-1715

[9] R. Ali Hadjesfandiari, A. Hadjesfandiari, Skew-symmetric couple-stress fluid mechanics, Acta Mech. 226 (2014) 871895

[10] A. Fatu, M. Hajjam, D. Bonneau, Analysis of non-Newtonian and piezoviscous effects in dynamically loaded connectingrod bearings, Proc. IMechE J: J. Eng. Tribol. 219 (2005) 209 224

[11] B.A. Gecim, Non-Newtonian effects of multigrade oils on journal bearing performance, Tribol. Trans. 33 (1990) 384-394

[12] P.S.Y. Chu, A. Cameron, Pressure viscosity characteristics of lubricating oils. J. Inst. Petrol. 48 (1962) $147-155$
[13] R.S. Paranjpe, Analysis of non-Newtonian effects in dynamically loaded finite journal bearings including mass conserving cavitation, J. Tribol. 114 (1992) 736-746

[14] P. Wang, T.G. Keith, K. Vaidyanathan, Non-Newtonian effects on the performance of dynamically loaded elliptical journal bearings using a mass-conserving finite element algorithm. J. Tribol. Trans. 44 (2001) 533-542

[15] P. Wang, T.G. Keith, K. Vaidyanathan, Combined surface roughness pattern and non-Newtonian effects on the performance of dynamically loaded journal bearings, Tribol. Trans. 45 (2002) 1-10

[16] M. Lahmar, B. Bou-Saïd, Couple stress effects on the dynamic behavior of connecting-rod bearings in both gasoline and diesel engines, Tribol. Trans. 51 (2008) 44-56

[17] J.F. Booker, Dynamically-loaded journal bearings: mobility method of solution, J. Basic Eng. 87 (1965) 537-546

[18] J.F. Booker, Dynamically-loaded journal bearings: numerical application of the mobility method, J. Lubrication Tech. 93 (1971) 168-174

[19] J.F. Booker, Mobility/impedance methods: a guide for application, J. Tribol 136 (2014) 024501

[20] A. Mouassa, H. Boucherit, B. Bou-Saïd, M. Lahmar, H. Bensouilah, S. Ellagoune, Steady-state behaviour of finite compliant journal bearing using a piezo-viscous polar fluid as lubricant, Mechanics \& Industry 16 (2015) 6

[21] W. Stachowiak Gwidon, W. Batchelor Andrew, Engineering Tribology, Elsevier Butterworth Heinemann, Burlington, 2005

[22] L.B. Sargent, Jr., Pressure-viscosity coefficients of liquid lubricants, ASLE Trans. 26 (1983) 1-10

[23] M. Lahmar, S. Ellagoune, B. Bou-Saïd, Elastohydrodynamic lubrication analysis of a compliant journal bearing considering static and dynamic deformations of the bearing liner, Tribol. Trans. 53 (2010) 349-368

[24] H. Boucherit, M. Lahmar, B. Bou-Saïd, Misalignment effects on steady-state and dynamic behaviour of compliant journal bearings lubricated with couple stress fluids, Lubrication Sci. 20 (2008) 241-268

[25] M. Lahmar, A. Belbah, D. Nicolas, Effets des deformations élastiques des revêtements de surface sur le comportement dynamique et la stabilité des paliers hydrodynamiques. Matériaux \& Techniques 11-12 (2002) (in French)

[26] K. Thomsen, P. Klit, A study on compliant layers and its influence on dynamic response of a hydrodynamic journal bearing, Tribol. Int. 44 (2011) 1872-1877

[27] D.G. Christopherson, A new mathematical method for the solution of oil film lubrication problems, Proc. IMechE 141 (1941) 126-135

[28] C.F. Gerald, P.O. Wheatley, Applied Numerical Analysis, 3rd edn., Addison-Wesley Publishing Company, 1984, ISBN 0-201-11577-8

[29] J. Campbell, P.P. Love, F.A. Martin, S.O. Rafique, Bearings for reciprocating machinery: a review of the present state of theoretical and experimental, and service knowledge, Proc. IMechE 182 (1967-1968) 51-74

[30] B.J. Hamrock, S.R. Schmid, B. Jacobson, Fundamentals of Fluid Film Lubrication, CRC Press, New York, 2004

[31] P.K. Goenka, R.S. Paranjpe, Discussion of the paper on a finite element cavitation algorithm by Kumar A. and Booker J.F., ASME J. Tribol. 113 (1991) 284-285

[32] D. Vijayaraghavan, D. E. Brewe, T.G. Keith, Effect of outof-roundness on the performance of a diesel engine connecting-rod bearing, ASME J. Tribol. 115 (1993) 538-543 
[33] B. Vincent, P. Maspeyrot, J. Frêne, Cavitation in dynamically loaded journal bearings using mobility method, Wear 193 (1996) 155-162

[34] P.K. Goenka, Dynamically loaded journal bearings: finite element method analysis, ASME J. Tribol. 106 (1984) 429-439
[35] C. Zhang, H. Zhang, Z. Qiu, Fast analysis of crankshaft bearings with a database including shear thinning and viscoelastic effects, Tribol. Trans. 42 (1999) 922-928

[36] J.D.C. Mc Ivor, D.N. Fenner, Finite element analysis of dynamically loaded flexible journal bearings: a fast Newton-Raphson method, J. Tribol. 111 (1989) 597-604

Cite this article as: B. Laouadi, M. Lahmar, B. Bou-saïd, H. Boucherit, A. Mouassa, Analysis of couple-stresses and piezo-viscous effects in a layered connecting-rod bearing, Mechanics \& Industry 19, 607 (2018) 